\title{
Genetic and molecular bases of cucumber (Cucumis sativus L.) sex determination
}

\author{
Magdalena Ewa Pawełkowicz $(\mathbb{D} \cdot$ Agnieszka Skarzyńska • Wojciech Pląder • Zbigniew Przybecki
}

Received: 21 February 2018 / Accepted: 27 February 2019 /Published online: 13 March 2019

(C) The Author(s) 2019

\begin{abstract}
Despite the importance of plant sex determination in genetic diversity, there is no clear picture of the regulation of this process. Cucumber has recently emerged as an excellent model system to explore sex determination. In this review, we describe the current state of sex determination in cucumber and propose a model to explain the regulation of the molecular processes controlling this phenomenon. Transcriptional profiling of hormonally controlled genes involved in sex-specific patterns of floral development has progressed from geneticbased studies to direct RNA analysis and from geneby-gene examinations to genomic-scale analyses. Floral development comprises an orchestrated series of processes that are ordered in accordance with plant genetic background. Moreover, they are regulated at multiple levels by endogenous and environmental factors. Recent findings have contributed to a better understanding of sex expression and will undoubtedly inspire new applications and research into mechanisms underlying the development, function, and evolution of cucumber sex determination and floral morphogenesis. Intensive investigation of potential sex determination genes in model species is anticipated to aid the elucidation of the sex determi-
\end{abstract}

\footnotetext{
M. E. Pawełkowicz $(\bowtie) \cdot$ A. Skarzyńska • W. Pląder • Z. Przybecki

Department of Plant Genetics, Breeding and Biotechnology, Faculty of Horticulture, Biotechnology and Landscape Architecture, Warsaw University of Life Sciences-SGGW, Nowoursynowska 159, 02-776 Warsaw, Poland e-mail: magdalena_pawelkowicz@sggw.pl
}

nation gene network and should have a significant impact on plant breeding.

Keywords Cucumber Ethylene $\cdot$ Floral development . Sex determination · Sex expression · Cucumis sativus L.

\section{Introduction—plant sex development}

Sex determination in higher plants is of fundamental biological interest and has great practical significance for fruit and seed production (Renner 2016). At several points during floral morphogenesis, this process is regulated on many omics levels by a complex regulatory network of interacting genes (Pawełkowicz et al. 2019). Three floral sex types can be described: male, female, and bisexual. The layout and proportions of flowers on a plant determine its sex. Plants producing only bisexual flowers are hermaphroditic. Species in which flowers of either sex are found on the same plant are said to be monoecious, whereas those in which each sex is housed on separate individuals are designated as dioecious. Many modifications of these three basic categories also exist.

Most plant species possess only bisexual flowers, i.e., those having both male and female organs and producing both types of gametes (Lebel-Hardenack et al. 1997). The presence of stamens and a pistil in a single flower facilitates self-pollination. Although the existence of several advantages, self-pollination could lead to the reduction of genetic diversity and worse adaptation to environment and pathogen attack, or inbreeding depression. Therefore, many plants have 
evolved systems to prevent self-pollination, such as staggered blooming times, the differing maturity times of male and female organs within bisexual flowers, selfincompatibility, and temporal and spatial separation of male and female reproductive organs.

In accordance with evolutionary principles, however, species that incorporate genetic variation during reproduction have a survival advantage and therefore are favored. While crossing, the genetic material is mixed together with another combination of alleles that may contain mutations that affect the viability of the species or may also weaken the resulting individuals, but these will probably be eliminated along with the natural selection. Plants having unisexual flowers can be monoecious where the male and female flowers are located on the same plant or dioecious where the male and female reproductive systems occur on separate plants. A number of intermediate phenotypes with varying proportions of flower types can also be described, such as andromonoecious, gynomonoecious, and trimonoecious. These forms and various processes controlling floral sex development evolved from an ancestor with bisexual flowers (Sun et al. 2010). Dioecious species are found in various genera and families but represent only $6 \%$ of all species. The distribution of this trait suggests that dioecy has arisen independently in several plant lineages (Renner 2014).

Genetic factors in plant sex determination

The simplest systems of sex-type inheritance are monogenic, while more complex mechanisms involve multiple loci and may include sex chromosomes. Various hormonal and environmental factors that control sex conversion also exist (Aryal et al. 2014). According to the classic theory, sex chromosomes evolved from a specific pair of autosomes along with the emergence of sex-determining genes ( $\mathrm{Li}$ et al. 2016b). Most of the higher plants have undifferentiated chromosomes; in dioecious plants, however, heterogametic male formation is usually dependent on the XY system (Grant et al. 1994). In this system, masculinity is generally conferred by the presence of a pair of heteromorphic chromosomes (XY), whereas individuals with homomorphic chromosomes (XX) are female (Lebel-Hardenack and Grant 1997; Lebel-Hardenack et al. 1997). In species such as Silene latifolia (Muyle et al. 2012) and Asparagus officinalis (Telgmann-Rauber et al. 2007; Li et al. 2014), males and females thus have $X Y$ and $X X$ karyotypes, respectively. In a few dioecious species, such as Fragaria elatior, sexuality is instead based on the ZW system, in which females are heterogametic (Vyskot and Hobza 2004, 2015).

Sex can also be determined by the number of $\mathrm{X}$ chromosomes to autosomes ratio, such as in Humulus lupulus or Rumex acetosa (Ainsworth et al. 1999). In Rumex, plants are female if the ratio of $\mathrm{X}$ chromosomes to autosomes is 1.0 or higher and male if the ratio is below the 0.5 . If the ratio is between 0.5 and 1.0 , bisexual flowers are formed (Ainsworth et al. 1999).

Epigenetic factors in plant sex regulation

Direct lability of sex expression by epigenetic regulation through DNA methylation, histone modifications, or the action of noncoding RNAs has been observed in many species (Piferrer 2013). In Melandrium album, DNA methylation is necessary to maintain the unisexual nature of male plants, and demethylation causes a reversion from male to hermaphroditic flowers (Janoušek et al. 1996). In contrast, demethylation in Elaeis guineensis causes abnormal floral development (Jaligot et al. 2011). In Cucumis melo, the insertion of transposable elements leads to DNA methylation of the WIP (WPP trp/pro/pro domain Interacting Proteins) promoter with the subsequent formation of female flowers (Martin et al. 2009). Several microRNAs (miRNAs) also regulate sex determination and floral morphogenesis (reviewed in $\mathrm{Li}$ et al. 2015). In Zea mays, for example, miRNA172 regulates the expression of the IDS1 (INDETERMINATE-SPIKLELET1) gene, whose differential expression determines differences in primordial initiation and thus regulates sex determination (Chuck et al. 2007).

Plant sex determination by hormonal and environmental factors

Plant hormones play a role in sex determination, but their exogenous addition has various effects in different species. In Asparagus officinalis, gibberellins have a masculinizing effect (Bracale et al. 1991), while in Mercurialis annua, cytokinins and auxin have masculinizing and feminizing effects, respectively (Durand and Durand 1991). In species such as Z. mays and Cucumis melo, ethylene, auxins, and cytokinins lead to female flower formation, while ethylene has the opposite role in Citrullus lanatus (Rudich 1990). 
Gibberellins induce male flowers in Spinacia oleracea (Ćulafić and Nešković 1980) but cause carpel development in Carica papaya (Kumar and Jaiswal 1984).

Environmental factors, such as photoperiod, light intensity, temperature, nutrition, and water dosage, can also influence sex expression in many species (Banks 2008; Chuck et al. 2007; She et al. 2009; Aryal et al. 2014). Given the variety of factors regulating and influencing floral formation, elucidation of the molecular mechanism(s) responsible for sex determination is an enormous challenge in plant biology.

Sex morphogenesis and floral meristem initiation

Clarification of the mechanism(s) of flower formation could aid in the development of new techniques for sex manipulation, not only in cucumber but also in other species to explain sex determination, studies of sexually reproducing plants attempt, among other things, to identify the primary signal leading to development of the particular flower sex and, more precisely, the development of particular organs in whorls (McKeown 1994; Tanurdzic and Banks 2004). Primary signals inducing sex development as well as the manner of signal transmission differ between species, and this may indicate two completely different ways of sexual development (Grant et al. 1994). Studies on sex determination mechanisms are very broad and have included analyses of genomes and transcriptomes from flower buds and flowers and the determination of mutual relationships between genes, the role of growth regulators and sexual stability or alteration in response to environmental changes (Durand and Durand 1991).

Analysis of homeotic floral mutants resulted in the formulation of a genetic model, named the ABC model (Coen and Meyerowitz 1991), and further it was expanded to include classes D and E. This model explains how the genes determine the identity of the flower organs. The development of sex-specific organs relies on the combinatorial and differential expression of homeotic genes over time and space (Guo et al. 2015). Based on the model, the A- and E-class complex (APETALA1 (AP1)-SEPALLATA (SEP)) specifies the sepal identity; A-, B-, and E-class proteins (AP1-SEPAP3-PISTILLATA (PI)) specifies petals; the B-, $\mathrm{C}-$, and E-class complex (AGAMOUS (AG)SEP-AP3-PI) specifies stamens; the C- and E- class complex (AG-SEP) specifies carpels; and the D- and E-class complex (SEEDSTICK (STK)-SEP) specifies ovules (Bowman et al. 2012; Guo et al. 2015). The MADS-box proteins bind DNA or can also show higher ordered protein-protein interactions (PPI). Even the individual amino acids change that altered PPI have the potential to affect phenotypic change (Bartlett et al. 2016).

Floral meristem arise from subapical stem cells and give rise to the floral primordia until homeotic genes are initiated. Prior to this developmental moment, MADS-box is silenced (Wils and Kaufmann 2016). For attention deserves chromatin regulators, which seem to be very important for the development of flowers. Basing on the Arabidopsis study, it was shown the ARABIDOPSIS TRITHORAX1 (ATX1) promotes upregulation of the floral homeotic genes through H3K4 methylation, then LFY (LEAFY) and SEP3 recruit the SWI/SNF (SWItch/ Sucrose Non-Fermentable) chromatin remodelers to activation the class $\mathrm{B}$ and $\mathrm{C}$ floral homeotic genes (Xiao et al. 2017).

During plant development, meristem identity is changed. One key change is conversion to flowering, where the vegetative meristem or shoot apical meristem transitions to an inflorescence meristem. One of the important aspects of meristem identity and plant architecture is phyllotaxis (Bartlett and Thompson 2014). Phyllotaxis refers to the arrangement of lateral organs around a central axis. Phyllotactic patterns are determined largely by auxin and cytokinin concentration in the meristem. Meristem identity refers to the type of primordia produced by a meristem, whereas meristem determinacy refers to the number of primordia produced and whether or not the meristem is consumed in the production of primordia. Meristem identity, determinacy, and phyllotaxis are interrelated and many plant developmental processes depend on them (Bartlett and Thompson 2014). This determines the need to conduct research on meristem dynamics research, not only on species such as Arabidopsis but also other important economic species. The exploration of diversity will allow a better understanding of the nuances underlying the principles of meristem shifting (Bartlett and Thompson 2014), flower formation, and sex determination. 
Primordial flower buds of most plants contain both stamen and pistil initials. Further bud development to form a unisexual flower occurs through inhibition of the development of the opposite sex primordial organs. Although the mechanisms leading to the inhibition of individual organs in bisexual buds have not yet been fully characterized, inhibition of "improper" primordial organs differs in various species. The evolution of unisexual forms from hermaphroditic flowers has been accompanied by the creation of various systems controlling flowering and sex development (LebelHardenack and Grant 1997).

Floral meristems exhibit a dynamic balance between cell proliferation and organ initiation. This process is genetically programmed to be terminated at a specific developmental stage after floral organ formation (Yamaguchi et al. 2017). This precise termination process allows floral meristems to form a female reproductive structure referred to as a gynoecium. In order to find factors that participate in this process, many molecular and genetic approaches have been performed, and Yamaguchi et al. presented a model describing how regulation of auxin homeostasis mediates the transition from floral meristem termination to gynoecium development. It is assumed that AG mediates floral meristem termination by targeting CRC (CRABS CLAW-involved in floral meristem development and auxin homeostasis) and $K N U$ (KNUCKLES - zinc finger proteins), which synergistically regulate floral meristem termination in two independent pathways. The direct AGAMOUS target CRC controls auxin homeostasis in the developing gynoecium through the negative regulation of TRN2 (TORNADO2 plasma membrane protein modulates auxin homeostasis), thus preventing the overgrowth of floral meristem. The AGAMOUS could also turn off the stem cell maintenance program by repression of WUSCHEL (WUS) (the key meristem maintenance gene) directly or indirectly by the $K N U$ gene. WUS expression begins to decline when $A G$ is activated (Yamaguchi et al. 2017). There are still many questions regarding floral meristem termination especially with the CRC pathway.

Interestingly, flower patterning and the activation of the floral homeotic genes are closely linked to flower meristem termination. ARF3 binds to the chromatin of WUS in an AG-dependent manner and directly represses WUS expression to promote floral meristem determinacy (Xiao et al. 2017).

\section{Cucumber sex development}

Cucumber as a model species

Because of their sexual lability, cucurbits, and cucumber in particular, have become an important system for studying the developmental genetics of sex determination (Malepszy and Niemirowicz-Szczytt 1991; Pawełkowicz et al. 2016a; Pawełkowicz et al. 2019; Grumet et al. 2017). Herein, we review some features of cucumber that make it a good model to study sex determination.

Cucumber is a diploid species with seven pairs of chromosomes $(2 n=2 \mathrm{x}=14)$ and an estimated genome size of $367 \mathrm{Mb}$. Genome sequences are available for three cucumber varieties: Chinese Long 9930 (GenBank: GCA_000004075.2), a Chinese variety sequenced in China by Huang et al. (2009; new version 2014); Gy14 (http://wenglab.horticulture.wisc.edu/), an American variety sequenced by the USDA-ARS Vegetable Crops Research Unit, Madison, WI (Cavagnaro et al. 2010); and B10 (GenBank: GCA_000224045.1), a northern European Borszczagowski line sequenced by the Polish Consortium of Cucumber Genome Sequencing (Wóycicki et al. 2011) and recently (2017) updated with PacBio reads (GenBank: LKUO00000000.2; (https://www.ncbi.nlm. nih.gov/Traces/wgs/?val=LKUO02\#contigs). The latter sequence covers $94 \%$ of the cucumber genome and is currently the most complete draft version (Osipowski et al. 2016).

Cucumber plants possess female, male, and bisexual flowers (Fig. 1) and can be described in various ways depending on position and occurrence of these flowers on the stem as: monoecious, gynoecious, andromonoecious, hermaphroditic, trimonoecious, or androecious. However, at the early stages of growth, flower buds look similarly, and the morphology of individual types of flowers is different and visible when buds are 3$5 \mathrm{~mm}$ long (Fig. 1). The main difference is the presence of stamens in male buds (Fig. 1a), pistils and ovaries in female buds (Fig. 1b), and both male and female organs in hermaphrodite buds (Fig. 1c). The difference is also visible in pedicels (stalks), which in male buds are thin and in female buds are thick and strong and show intermediate thickness in hermaphrodite types. Ovaries of female and hermaphrodite buds vary, female's ovary is smaller and more elongated looking like a "tiny" cucumber, whereas a hermaphrodite ovary is shorter and bulgier. Precise systematic morphogenetic analysis of floral 

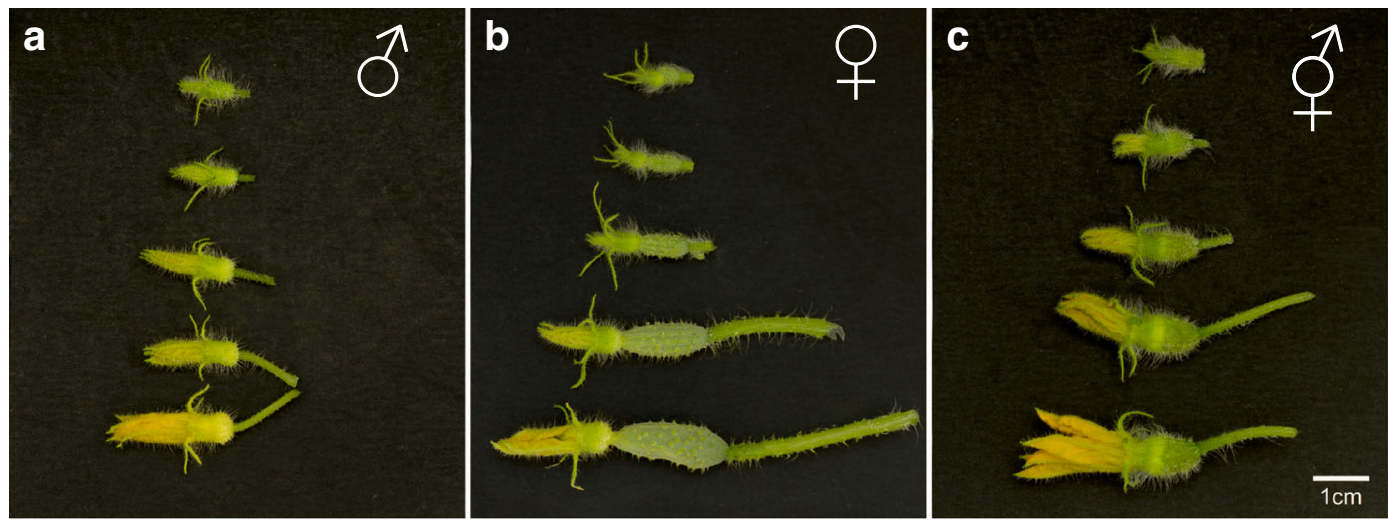

Fig. 1 Development of cucumber flowers. The pictures show male (a), female (b), and hermaphroditic (c) flower buds at successive developmental stages

development in cucumber was conducted by Bai et al. (2004). According to the existence of distinct morphological events, they divided unisexual flower development into 12 stages ranging from floral meristem initiation to anthesis. During the first five stages (up to $\sim 0.5 \mathrm{~mm}$ ), morphological changes are identical in both sex types. In later stages $(\sim 0.6$ to $40 \mathrm{~mm})$, increasing differences are evident between female and male flowers.

Mechanisms of organ development in cucumber flower buds

Immediately after formation, cucumber floral buds are hermaphroditic and possess both stamen and pistil primordia. Unisexual floral development begins through the inhibition of the primordial organs of the opposite sex when buds are about 0.5 to $2 \mathrm{~mm}$ long (Hao et al. 2003; Bai et al. 2004). At the next stage when 3-5 mm long, a bud is already sexually determined. Development of primordial pistils or stamens then continues according to the sexual type of the mature flower. In the case of female flowers differentiation, which takes place after stamen differentiation into filament and anther, the anther, but not the complete stamen, is inhibited. In the study of this phenomenon in cucumber female flower buds, the activity of likely anther-specific DNases and chromatin condensation was observed in primordial stamen anthers, but the mitochondria and nuclei remained unchanged and programmed cell death (PCD)-characteristic laddering was noted. Although some PCD-connected phenomena were detected in differentiating buds, the responsible mechanism was not the same as that operating in maize where PCD is responsible for the inhibition of opposite sex organ development (Calderon-Urrea and Dellaporta 1999; Hao et al. 2003). It was found that developmental arrest of the inappropriate stamen occurs mainly in the anther primordium. This inhibition was correlated with DNA damage, detected by the TUNEL assay. The authors conclude that this is the result of anther-specific DNase activation. It was also found that DNA damage does not lead to cell degeneration, although chromatin condensation was observed in the anther primordia (Hao et al. 2003). Female organ inhibition processes in male flower buds have not yet been sufficiently explained. Some researchers have observed DNA laddering in male buds, which may be an evidence of stamen inhibition through PCD (Delorme et al. 2000).

However, in cucumber, Yang et al. (2000) showed that primordial pistils remain metabolically active during male flower development. Because treatment of cucumber protoplast cultures with ethephon activates endogenous DNases that damage cellular DNA, ethylene has been proposed to be a possible inhibitor of male organ growth in female flowers via PCD (Wang et al. 2010). To date, the identity of the primary signal triggering the development of particular floral sex types remains unknown.

To investigate the correlation between sexual organ cell cycle activity and sex expression, Yamasaki et al. (2017) analyzed the expression of six cell cycle-related genes in cucumber ( $C s C y c A, C s C y c B, C s C y c D 3 ; 1$, $C s C y c D 3 ; 2, C s C D K A$, and $C s C D K B$ ) in male and female flower buds. $C s C y c A$ gene was specifically expressed in the area containing arrested stamen primordia (ACASP) but was barely detected in male flower buds. Expression of the other five genes was detected in the ACASP but not in pistils of female 
flower buds. In addition, the epidermal cell number per square millimeter of male flower buds did not differ significantly between petals and stamens; in female flower buds, however, the epidermal cell density of arrested stamen primordia was much greater than that of petals. These results support the conclusion that cell division is maintained at a high rate in the ACASP of female flower buds (Yamasaki et al. 2017). The observed distribution of epidermal cells combined with the results of the studies of cell cycle-related gene expression and PCD in floral buds suggests the following scenario: although cell division activity is maintained at a high rate, cell growth is restrained, and finally, PCD occurs in the arrested stamen primordia of female flower buds of monoecious cucumber plants (Yamasaki et al. 2017).

Genetic factors controlling sex determination in cucumber

Even strictly monoecious, cucumber plants display remarkable sexual plasticity. The main stem of monoecious cucumbers is characterized by three phases of floral sex development. In the initial (male) phase, flowers are produced at lower nodes. In the second phase, male and female flowers are formed in the middle part of the plant, while flowers prevail at the upper nodes during the third (female) phase. Genetic studies have determined that sex expression in cucumber is controlled by four main loci, $F, M, A$, and $G y$ (Malepszy and Niemirowicz-Szczytt 1991), and by genes that can slightly change floral phenotypes:

- $F$ (female) - Plants with the dominant $F$ allele are female (dominant femininity dF). Expression of this gene is influenced by other sex genes and the environment, a situation called "soft femininity." Lines homozygous for the dominant $F$ allele are female. The $F$ locus has been cloned and shown to be an additional copy of the CsACS1G gene encoding 1aminocyclopropane-1-carboxylic acid synthase (ACS) (Trebitsh et al. 1997; Mibus and Tatlioglu 2004).

- $m$ (andromonoecious) - This recessive allele has an influence on the bisexual flower creation. Plants with the genotype mmff are andromonoecious and those with $m m F_{-}$have hermaphroditic flowers. Flowers of plants harboring $M_{-} F_{-}$are female, whereas $M \_f f$ plants are monoecious with mostly male flowers. The $M$ locus has also been cloned and shown to be the CSACS2 gene encoding another member of the ACS family ( $\mathrm{Li}$ et al. 2009), while the $m$ allele has a mutation at a conserved site (Gly33Cys). This isoform displays reduced enzymatic activity (Boualem et al. 2009; Li et al. 2009).

- a (androecious) - aa homozygotes are characterized by the intensification of male features. The gene is hypostatic to the $F$ gene. Plants with the genotypes mmffaa and $M_{-} f f a a$ are completely male. According to Boualem et al. (2015), this gene may be connected with CSACS11.

- gy (gynoecious) - This recessive allele is responsible for femininity that is much more highly stable than that conferred by the $F$ gene (recessive femininity $\mathrm{rF}$; "hard femininity"). The $g y$ gene (also abbreviated as $g$ ) is frequently assumed to be the gene indirectly influencing sex (Pawełkowicz et al. 2012) and it could be correlated with CsWIP (Boualem et al. 2015).

- $h$ (andromonoecious-2) - This allele produces bisexual flowers with normal ovaries (Kubicki 1974).

- In-F (Intensifier of female sex expression) - causes intensification of $F$ gene action (Malepszy and Niemirowicz-Szczytt 1991).

- $\operatorname{Tr}$ (Trimonoecious) - This regulates the formation of female, male, and bisexual flowers, but the ratio of the different types of flowers could be influenced by environmental factors (Kubicki 1969c).

Whereas information on the function of the $F$ and $M$ genes is described, little is known about the functions of $A / a, G y / g y$, and $H / h$ alleles. In one study, the $A / a$ allele was suggested to be linked to the copper transporter gene CsRAN1 (Terefe 2005), whereas the dominant allele $G y / g y$ gene can be correlated with the putative serine/threonine kinase gene CSPSTK1 (Pawełkowicz et al. 2012). Because CsPSTK1 expression is related to the recessive $g y$ allele, the associated inhibition of the CSPSTK1 gene may require the presence of the dominant $G y$ allele. Presumably, CSPSTK1 inhibition by the $G y$ allele negatively affects ethylene biosynthesis. When $g y$ is present, the inhibition is removed and the CSPSTK1 gene has a positive effect on ethylene levels (Pawełkowicz et al. 2012). According to recent reports, the recessive female state is conditioned (similar to Cucumis melo) by mutational changes in the WIP (CmWIP1-CsWIP1) gene, which possesses a zinc finger 
domain and controls transcription (Martin et al. 2009; Boualem et al. 2015; Chen et al. 2016).

Despite the above findings, the mechanism of sex determination is far more complicated than detailed above, and many other genes are correlated with this process in cucumber (summarized in Table 1). The functions of these genes are discussed later in this article.

Expression analysis of genes participating in ethylene perception in cucumber

The plant hormone ethylene plays an important role in sex determination in cucumber and counteracts the role of other hormones (Yin and Quinn 1995). Ethylene biosynthesis and its signaling pathway have been the subject of numerous studies that have proven the importance of this hormone in cucumber (Ando et al. 2001a, b; Boualem et al. 2008, 2009; Sun et al. 2010; Tao et al. 2018; Wang et al. 2010; Yamasaki et al. 2003a, b).

Ethylene is produced in the Yang cycle metabolic pathway starting from methionine, its precursor in higher plants (Fig. 2). The next compound in the cycle is Sadenosylmethionine (SAM), which is synthesized during plant growth and development (Adams and Yang 1979). SAM is decomposed into 5'-methylthioadenosine (AdoMet) and 1-amminocyclopropane-1-carboxyl acid (ACC). Under anaerobic conditions, this reaction is catalyzed by ACC synthases (ACS) (Oeller et al. 1991) whose activity is inhibited by aminoethoxyvinylglycine (AVG), aminooxyacetic acid (AOA) and $\mathrm{CO}_{2}$. A whole family of genes codes for ACC synthases and their expression is variable depending on the plant species and environmental influences (Oeller et al. 1991). The intensity of conversion SAM into ACC is a regulating factor in ethylene production. In the final step, ACC is converted into ethylene in the presence of oxygen by ACC oxidases (ACO) encoded by a group of $A C O$ genes.

\section{ACC synthase genes}

ACC synthases are encoded by a family of genes. Six $A C S$ genes have been identified in cucumber: CsACS1, CsACS1G, CsACS2, CsACS3, CsACS4, and CsACS11 (Boualem et al. 2015, 2016; Kamachi et al. 1997; Trebitsh et al. 1997; Shiomi et al. 1998). In this review, we use the nomenclature adopted by Kamachi et al. (1997), Trebitsh et al. (1997), and Yamasaki et al. (2003a). Under this convention, CsACS1 is an auxin- inducible ACC synthase coding gene and CsACS3 is induced by wounding and $\mathrm{CO}_{2}$ stress.

Trebitsh et al. (1997) detected a homolog of the CsACS1 gene, CsACS1G, in female cucumber plants. They also observed a $100 \%$ correlation between the occurrence of the dominant $F$ allele and CSACS1G. Comparison of the 50-bp flanking regions of CsACS1 and CsACS1G has revealed that their sequences are identical up to 607 bp upstream (Kieber et al. 1993). While differences exist between the distal promoters of the two genes, their proximal promoters are very similar, which suggests that the different expression patterns between them are either due to regulation by the distal promoter or posttranslational modifications (Knopf and Trebitsh 2006; Yamasaki et al. 2000). The promoter region of the CsACS1G gene is longer than that of CsACS1 (Yamasaki et al. 2000). The strong similarity of these two genes suggests that the gynoecious $(F F)$ genotype arose through a duplication in monoecious cucumber. According to the genetic map developed by Miao et al. (2011b) with microsatellite markers, the $F$ gene $(C s A C S 1 G)$ is located on chromosome 6. Expression analysis has shown that $\operatorname{Cs} A C S 1 G$ transcription is promoted by auxins and inhibited by gibberellic acid. Cloning and sequencing of the $F$ locus has provided evidence identifying this region as the CSACS1G gene (Kieber et al. 1993). A study on cucumber plants using RNA interference (RNAi) has subsequently confirmed this assignment. In addition, inhibition of CSACS1G expression in that study led to monoecy, thus verifying the involvement of the $F$ locus in sex determination (Mibus and Tatlioglu 2004).

In addition to the above findings, CsACS2 displays the most abundant expression in gynoecious and monoecious cucumber plants (Mibus and Tatlioglu 2004). Subsequent analyses have proven that CsACS2 cosegregates with the $M$ locus in cucumber and that CsACS2 transcript levels in the leaves are positively correlated with node number on the main stem (Kahana et al. 1999; Perl-Treves 1999). CsACS2 expression is reduced in monoecious cucumber plants relative to gynoecious ones, with transcript accumulation detected below the pistil primordia (Yamasaki et al. 2003b). In monoecious cucumbers, CSACS2 has also been found to accumulate only in some flowers situated at certain nodes (Wang et al. 2012). In situ hybridization has shown that the gene is mainly expressed in the ovary and in areas later developing into ovules of female and hermaphroditic flowers (Kahana et al. 1999). According 


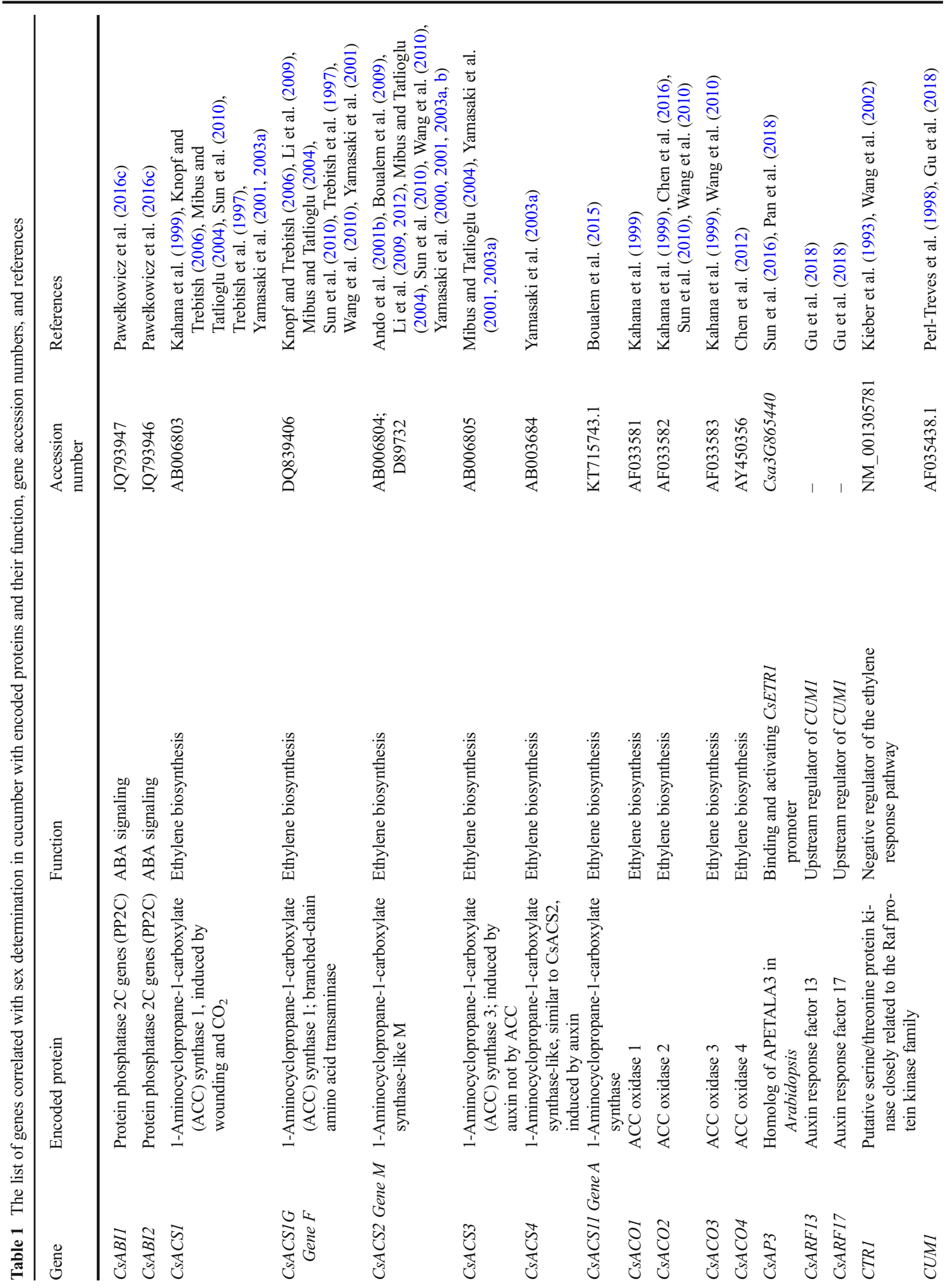




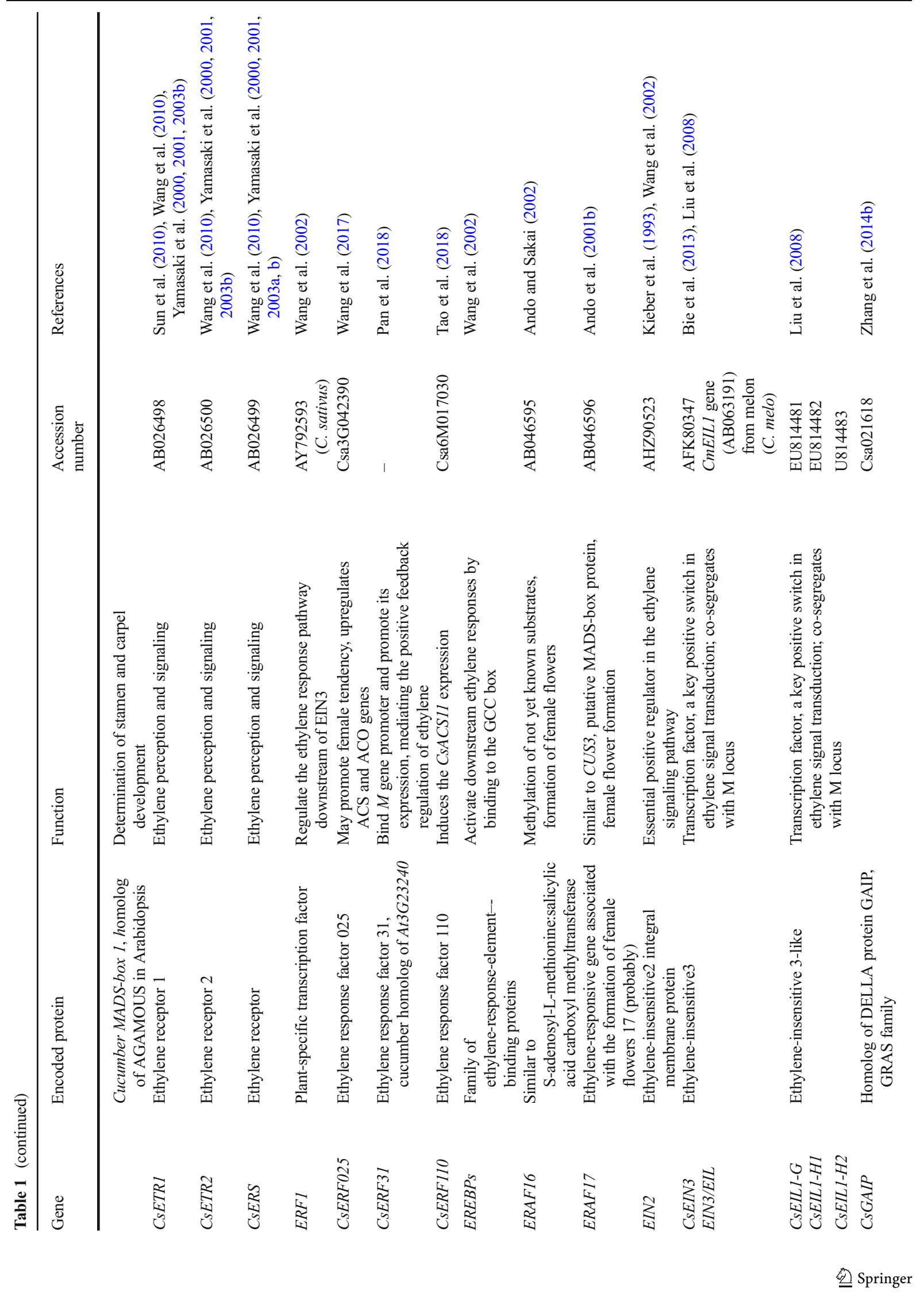




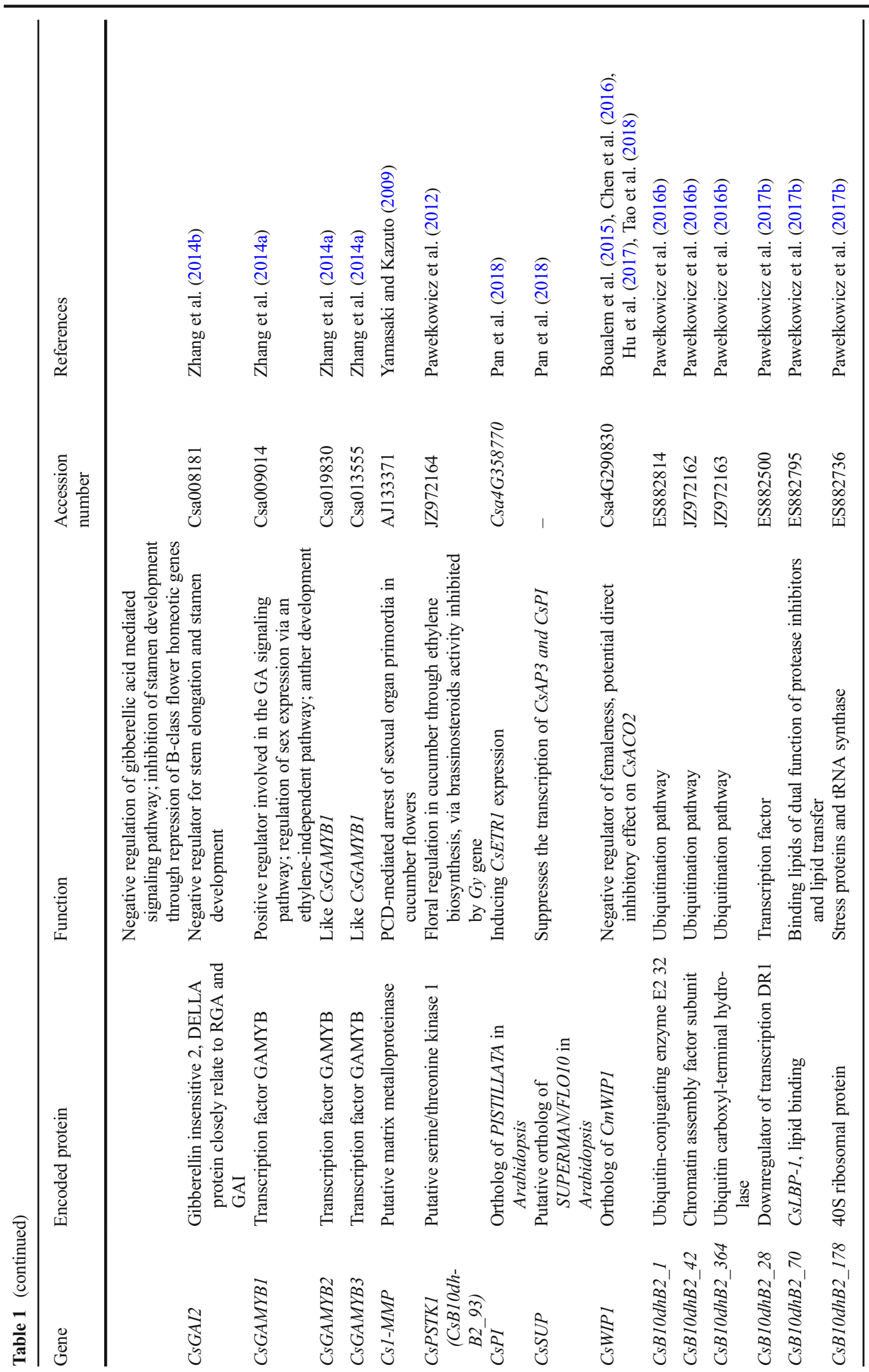




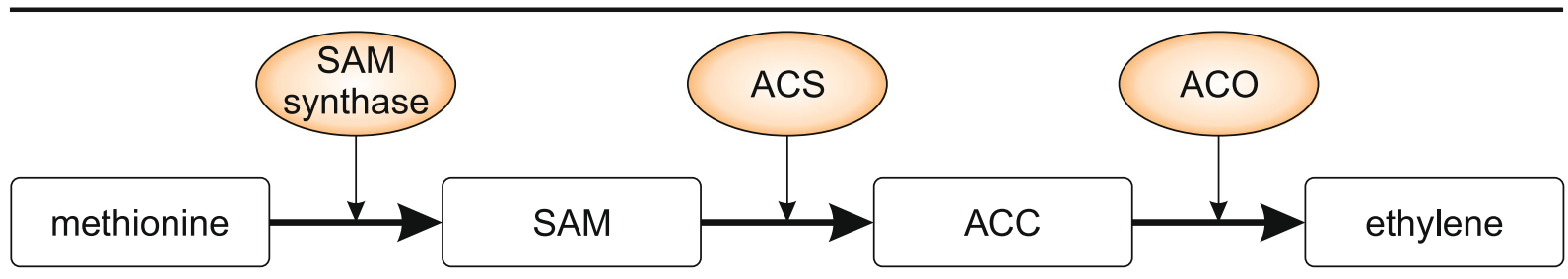

Fig. 2 Scheme of ethylene production from its methionine precursor via SAM synthases, ACC synthases, and ACC oxidases

to Yamasaki et al. (2001), the $M$ gene is epistatic to the $F$ gene and, being ethylene inducible, may be involved in the amplification of ethylene production through positive feedback (Yamasaki et al. 2003a; Li et al. 2012).

The sequences of two remaining genes, CsACS 3 and CsACS4, have been found to be very similar to those of previously identified $C S A C S 1$ and $C s A C S 2$, respectively (Yamasaki et al. 2003a). These genes differ in terms of their induction. CsACS3, a close homolog of CsACS1 and $C S A C S 1 G$, is induced by wounding and is responsible for the enhancement of ethylene biosynthesis under $\mathrm{CO}_{2}$ stress conditions. Cycloheximide reduces CsACS3 transcript accumulation (Mathooko et al. 1999). Nevertheless, CsACS3 transcripts have not been detected in gynoecious plants (Kamachi et al. 1997). Expression of the CsACS4 gene (homolog of CsACS2) is induced by auxins (Shiomi et al. 1998) but is not regulated by ethylene through the product of the $M$ locus (Yamasaki et al. 2003a). In a recent study, Lee et al. (2018) revealed that five genes-CSACS1, CsACS1-2, $C s A C S 2, C s A C S 6$, and CsACS11-were highly expressed in the shoot apex of hermaphrodite and gynoecious plants compared to monoecious. After exogenous ethylene treatment, the expression of most CsACSs was induced. Three isoforms showed no enzymatic activity, and this was associated with variation in the conserved active residues of CsACS proteins (Lee et al. 2018).

\section{ACC oxidase genes}

The results of research on ACC synthase have encouraged studies on the second enzyme taking part in the third and final stage of ethylene synthesis: ACC oxidase. This enzyme oxidizes the ACC compound into ethylene in the presence of oxygen.

The first reports of cloning of genes encoding ACC oxidases and their connections to sex expression in cucumber date back to 1999 (Kahana et al. 1999). In that study, sequences identified as CsACO1, CsACO2, and $C s A C O 3$ were isolated from a cDNA library constructed from female flower buds at the 1-mm stage, with a tomato ACC oxidase sequence used as a probe. Analysis of $\mathrm{Cs} A C O 2$ gene expression in the leaves and shoot apices revealed differences between genotypes and studied organs. CsACO2 gene transcript levels were lower in shoot apices and flower buds of dominant $F F$ homozygotes (female and hermaphroditic) and higher in recessive $f f$ (male and monoecious) lines. In addition, transcript levels decreased in the monoecious line at the beginning of flower bud formation. Low transcript levels in the apex were correlated with high levels in the leaves. The higher content of the gene product in young leaves compared with shoot apexes as well as high levels in male lines suggests the possible existence of a negative correlation, possibly the result of an inhibitory association. A feedback phenomenon may also exist, in which an excessive ethylene concentration may inhibit its own synthesis by repressing CsACO gene expression (Kahana et al. 1999). The influence of the $\mathrm{CsACO} 4$ gene on sex expression in cucumber was studied by Chen et al. (2012) using transgenic plants obtained by RNAi. The inserted RNAi fragments inhibited endogenous $\mathrm{Cs} A \mathrm{CO} 4$ gene expression and were able to regulate male differentiation in the lower nodes of cucumber plants.

$A C S$ and $A C O$ genes may act during stages critical for sex differentiation by modulating ethylene concentration levels, which in turn may directly or indirectly cause the formation of the corresponding flowers (e.g., female ones). These sex-differentiating signals are formed in the shoot apex or flower buds independently of reduced CsACO transcript levels in surrounding cells. Ethylene production regulating sex expression could possibly occur in upper young leaves, where its concentration is positively correlated with $A C O$ transcript levels, with the signal then transmitted to flower buds through a yet unknown pathway (Kahana et al. 1999; Perl-Treves 1999). A more recent study investigating the reception and transmission of the ethylene signal as well as tissue susceptibility to this hormone has revealed that the cucumber CsWIP1 protein binds to the promoter 
of $C s A C O 2$ to repress its expression. $C s A C O 2$ is necessary for female flower determination and cooperates with CSACS11 to provide ethylene for carpel development (Chen et al. 2016).

\section{Relationships between ethylene and cucumber sex genes-genotype-dependent networks}

Based on the experiments of Kubicki (1969a, b, c) involving $F$ and $M$ genes, Yamasaki et al. (2001) formulated a hypothesis on the role of $F$ and $M$ genes and ethylene in sex determination. By comparing female and monoecious genotypes, Yamasaki et al. (2001) inferred that loss of the dominant $F$ allele leads to male flower production because stamen development is consequently induced and pistil development inhibited in the flower bud. The $F$ gene was thus proposed to simultaneously inhibit stamen and induce pistil development, with the $M$ gene epistatic to the $F$ gene. Combining all the previous data for $F$ and $M$, a model for sex determination was proposed by $\mathrm{Li}$ et al. (2012). According to those authors, the $M$ gene is activated by ethylene, and a positive feedback mechanism leads to permanent arrest of stamen development.

The Gy gene, which is assumed to regulate CSPSTK1 gene activation, may also be involved in sex determination (Fig. 3). The dominant Gy gene inhibits CSPSTK1, which has a positive influence on ethylene production (Pawełkowicz et al. 2012).

Plants with $F_{-} M_{-} G y_{-}$genotypes can produce a sufficient quantity of ethylene in their primordial flowers to induce development of female floral elements (pistils). The $F$ locus is probably the first gene activated in primordial buds. The CSACS1G gene promotes ethylene synthesis and pistil development; at the same time, stamen development is inhibited by the presence of an $M$ allele. This positive feedback provides a constant high level of ethylene, with stamen inhibition appearing in all flower buds (Li et al. 2012). In this case, the ethylene level is so high that the presence of the $G y$ allele does not influence female flower formation because the level of ethylene is sufficinet.

In monoecious plants ( $f f M_{-}$), the lack of the $F$ allele hinders the production of sufficient quantities of ethylene to induce female organs in all flower buds, whereas stamen development can be inhibited by the presence of the dominant $M$ allele. In some flower buds, pistils consequently develop, stamen development is inhibited
Fig. 3 A hypothetical scheme of the correlation between $F, M, A$, and $G y$ loci and their influence on floral differentiation in cucumber. a Plants with dominant $F$ and $M$ alleles produce a quantity of ethylene sufficient for induction of pistil development. The $M$ allele facilitates the arrest of stamen development. b Despite the presence of the recessive $f$ allele, plants with the genotype $f f M \_g y g y$ can produce enough ethylene for pistil development thanks to the activity of the CSPSTK1 gene not inhibited by the recessive $g y$ allele. Stamen development is inhibited by the $M$ locus. $\mathbf{c}$ In monoecious lines, the absence of the $F$ allele combined with the presence of the dominant $G y$ allele, which inactivates the CSPSTK1 gene and inhibits an ACO gene, causes ethylene production to be insufficient to initiate pistil development in all flowers. Nevertheless, flowers with the stem development-arresting $M$ allele are female, whereas those with the recessive $m$ allele are male. d In hermaphroditic plants, the presence of the dominant $F$ allele facilitates the production of enough ethylene for induction of pistil development, while the absence of the dominant $M$ allows for stamen development

( $M$ allele), and female flowers occur. In other buds, neither induction of pistil development nor stamen inhibition occur ( $m$ allele); thus, a male flower develops. Monoecious plants therefore produce both male and female flowers on the same plant.

Whether or not a plant with the genotype $f f M_{-}$is monoecious depends upon the presence or absence of the dominant $G y$ allele. As previously mentioned, the Gy locus is associated with the CSPSTK1 gene, whose product positively influences ethylene biosynthesis or signalling. Because the dominant $G y$ allele inhibits CSPSTK1 expression, a plant with the $f f M_{-} G y_{-}$genotype is monoecious. In the presence of a recessive gy allele, however, the inhibitory effect is abolished, CSPSTK1 promotes ethylene signalling cascade, and despite the presence of the recessive $f$ allele, the plant posses enough ethylene for pistil promotion. This level of ethylene is also sufficient for induction of the $M$ gene and activation of positive feedback. Plants with the genotype $f f M \_g y g y$ are therefore gynoecious (Pawełkowicz et al. 2012).

In the flowers of hermaphroditic plants $\left(F \_m m\right)$, stamen development probably constitutes a reduced response to ethylene. The presence of just the recessive allele $m$ leads to stamen development in all flower buds. Because these plants possess an $F$ allele, they can produce a sufficient quantity of ethylene to develop pistils as well.

In andromonoecious (mmff) plants, the presence of two $m$ alleles does not lead to inhibition of stamens; on the contrary, stamens are present in all flowers. Because 


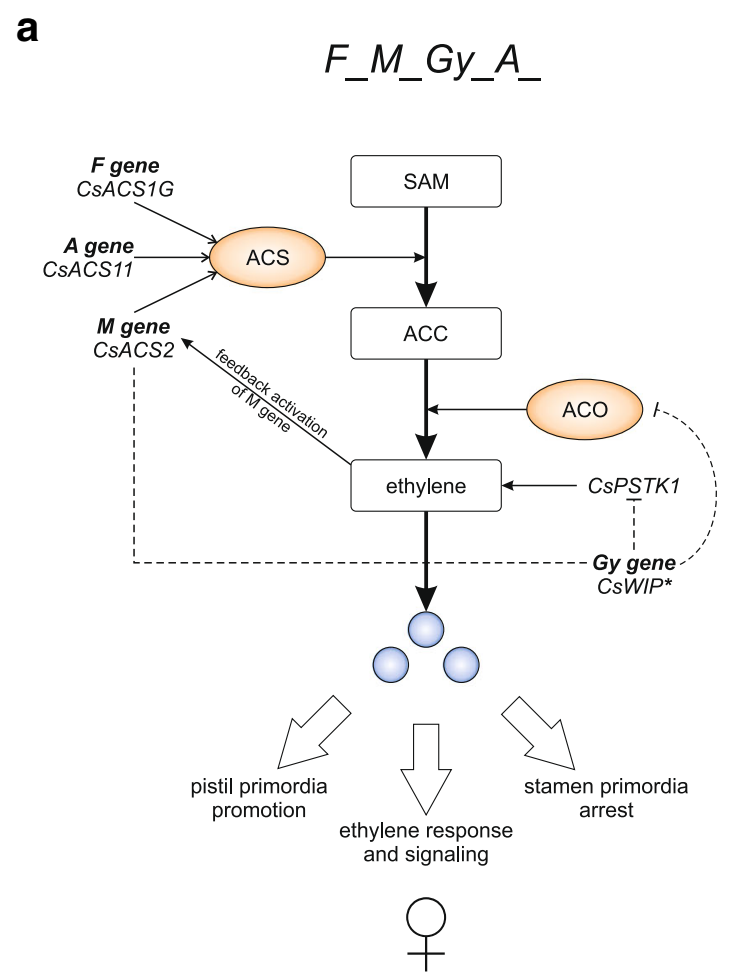

b

ffM_gygyA

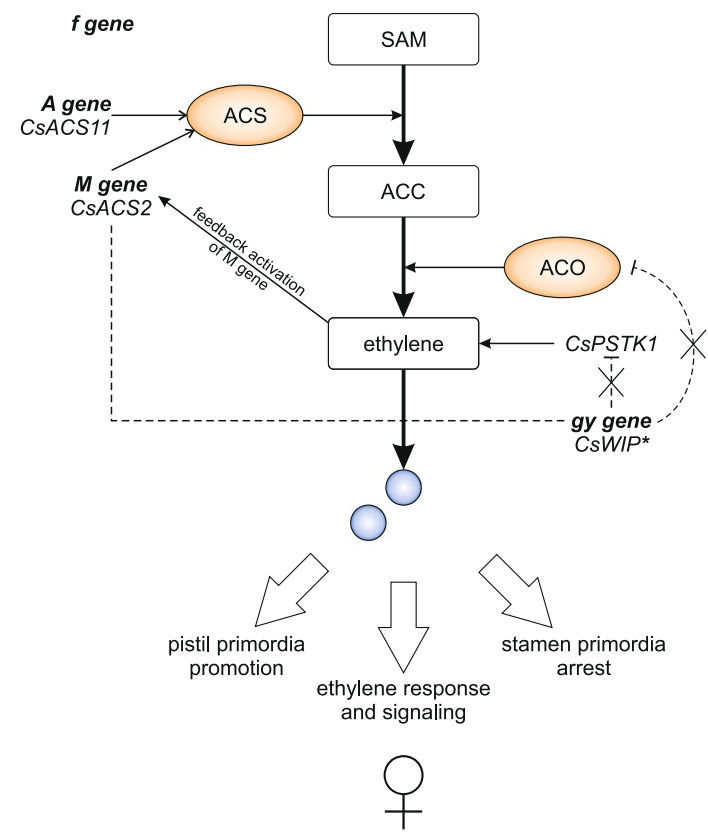

d

$F_{-} m m G y \_A_{-}$
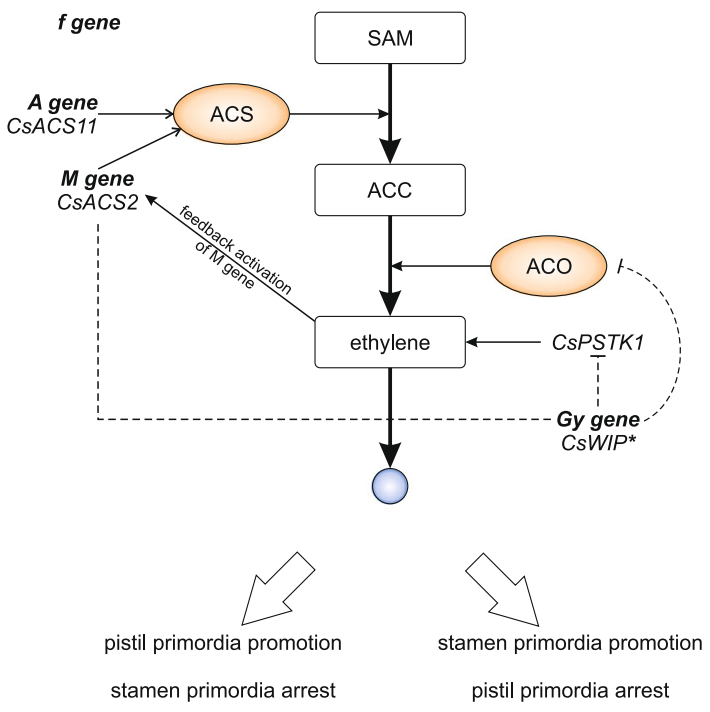

$9 \pi$ 
no dominant $F$ allele is present, primordial flowers lack enough ethylene to induce pistil development; nevertheless, pistils develop in some flowers, and the resulting flowers are bisexual. Consequently, andromonoecious plants produce male and bisexual flowers.

Although hypothetical, the above-described model of the ethylene biosynthetic functions of $F$, $M$, and $G y$ genes is consistent with various findings. In particular, this model is in agreement with the results of comparative analyses of ethylene biosynthesis gene expression and ethylene receptors in flower buds as well as concentration measurements of ethylene emitted from female and male plants. Studies clearly show that sex determination in cucumber is an ethylene-controlled process (Yamasaki et al. 2001).

Using positional cloning and a TILLING strategy, Boualem et al. (2015) revealed that the $a$ allele corresponds to the CsACS11 gene, which encodes an additional enzyme in ethylene biosynthesis. The dominant $A$ allele of CSACS11 is necessary for the development of female flowers in monoecious Cucumis species. The loss of ACS11 activity triggers a female-to-male gender transition. Male mutants treated with ethephon develop female flowers. In addition, ACS11 mRNA can be detected in female flowers; it is also highly expressed in the phloem of hermaphroditic buds but is not found in males. The expression of CsACS11 in the phloem suggests that ethylene is the signal controlling the sex of flowers on the branch stems. Sequence analysis of the $a$ locus has revealed a single nonsynonymous nucleotide deletion. Whether mRNA or protein or ethylene is the signal finally controlling sex is not known (Boualem et al. 2015). Lastly, it was shown that ethylene signals are involved in the regulation of CSACS2 and CsACS11 at the transcriptional level involving CSERF110 (Tao et al. 2018).

Although the $\mathrm{m}$ and $\mathrm{F}$ genes play a major role in flower formation, genes such as $g y, h, I n-F$ and $T r$ are also involved in sex determination in cucumber (Malepszy and Niemirowicz-Szczytt 1991). Considering the results of a study in melon-another Cucumis species - gy is presumably a member of the WIP family. The WIP gene in melon encodes a transcription factor domain $\mathrm{C}_{2} \mathrm{H}_{2}$ zinc finger protein (Martin et al. 2009; Boualem et al. 2008, 2015; Renner 2016). This gene controls the development of male flowers, as the loss-of-function mutant carrying the recessive form produces only female flowers (Boualem et al. 2008).
In melon, CmACS11 is thought to act upstream as a negative regulator of expression of $C m W I P 1$, which then negatively regulates the expression of CmACS7 (Switzenberg et al. 2014; Boualem et al. 2015). Taking into account the allelic relations, expression is dependent on CsACS11 (Chen et al. 2016), whereby the $M$ gene is not expressed in the line possessing genotypes: ffMMaa and both ffMMaa and ffmmaa (corresponding to androecious plants) (Kubicki 1969a). In monoecious and andromonoecious plants, male flowers are thought to result from nonexpression of CsACS11 and CsACS2, while female flowers develop because expression of CsACS11 could repress CsWIP1 (Boualem et al. 2015, Tao et al. 2018). Previous studies suggest that ethylene induces CsACS2 and inhibits CmWIP1 expression in cucumber and melon, respectively ( $\mathrm{Li}$ et al. 2012; Switzenberg et al. 2014). Although no natural mutant of the $g$ locus has yet been described in cucumber, CRISPR/Cas9 analysis suggests that its orthologous gene, $C s W I P 1$, is related to arrested carpel development (Hu et al. 2017) via direct depressing in CsACO2 expression (Chen et al. 2016). The obtained Cswipl mutants possess female and hermaphroditic flowers compared to monoecious wild-type plants. Additionally, wild-type plants bear four female flowers on average, and the Cswipl mutant had seven times more female flowers than the wild type (Hu et al. 2017).

Genes $h, I n-F$, and $\operatorname{Tr}$ have not been well characterized; however, it is known that they can indirectly influence sex determination. Gene $h$ (also known as $m$ 2, andromonoecious 2) is related to development of bisexual flowers with normal ovaries (Kubicki 1974). Gene In-F (Intensifier of female sex expression) increases femaleness by increasing the female sex expression degree in plants with dominant $F$ allele (Kubicki 1974). Trimonoecious gene $\operatorname{Tr}$ regulates the formation of female, male, and bisexual flowers, but the ratio of the different types of flowers could be influenced by environmental factors (Kubicki 1969c).

Ethylene receptors and the ethylene signaling cascade in cucumber

The first step in the reception of the ethylene signal is the binding of the hormone molecule to a receptor site in a cell, usually to a specific protein located on the plasma membrane. A set of biochemical reactions is then initiated that influences target gene expression and leads to changes and formation of a particular physiological 
a

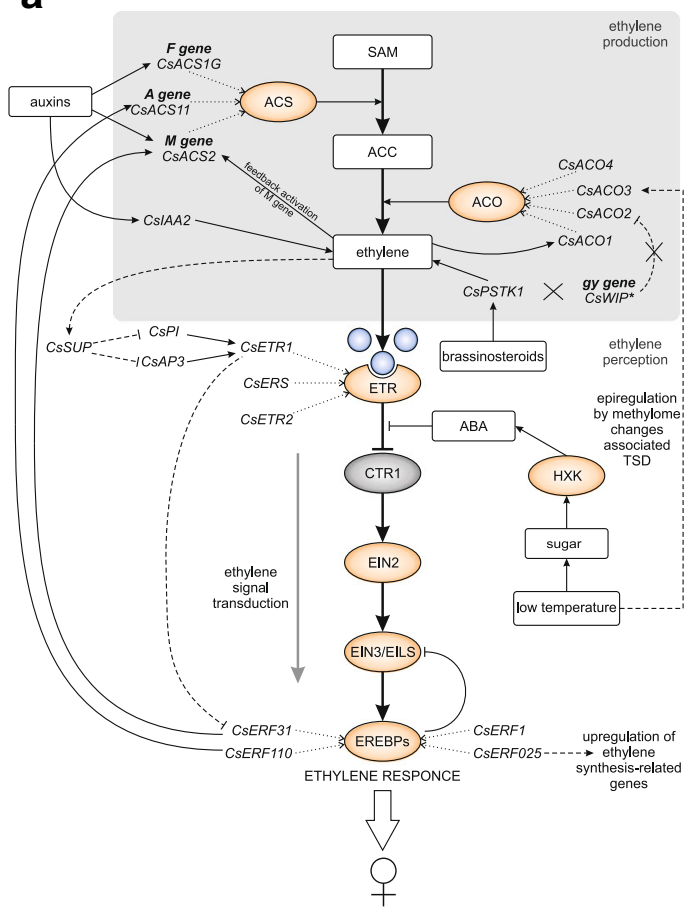

b

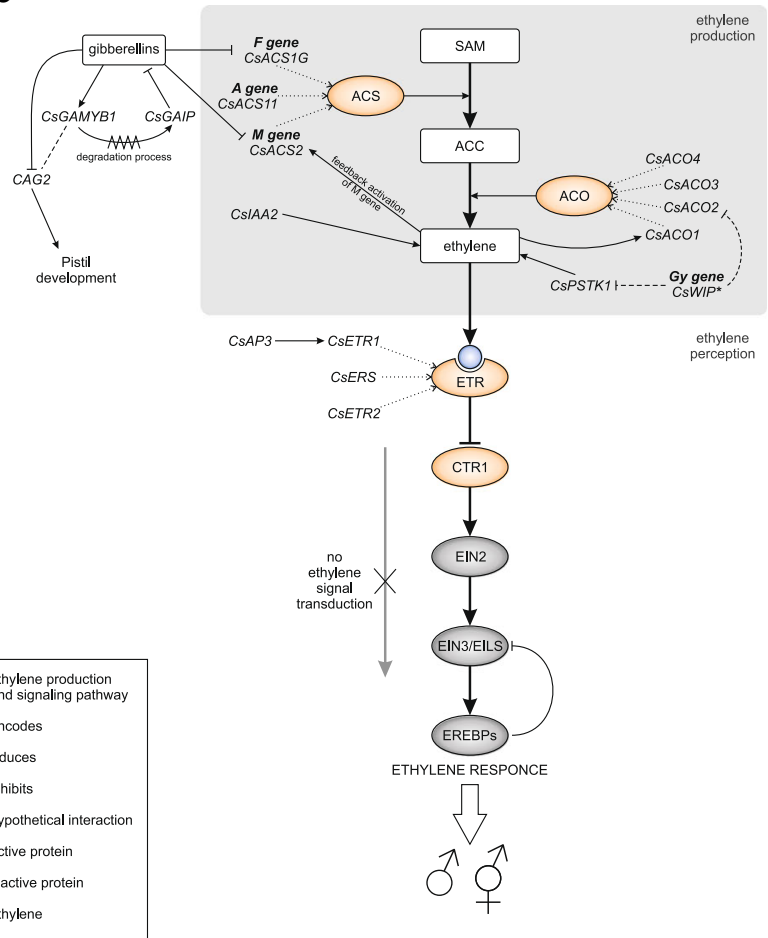

Fig. 4 A hypothetical model of the sex determination process showing interactions of genes, proteins, and phytohormones. Genes encoding ACC synthases $(F, M$, and $A)$, and ACC oxidases are involved in sex determination in cucumber through regulation of ethylene biosynthesis. The $G y$ gene may also be indirectly engaged in this process. a In the presence of ethylene, CTR is

effect. Differences in ethylene susceptibility between male and female buds indicate different perceptions and responses between primordia. Higher ethylene levels may be required for stamen inhibition than for stimulation of pistil development. Key factors in sex determination are therefore not only the production of ethylene but also the perception and signal transduction of this hormone (Wang et al. 2012).

Complete sequences of three cucumber ethylene receptor genes, CsETR1, CsETR2, and CsERS, have been isolated, and accumulations of the products of these genes in various developmental stages were studied in monoecious $(M f f f)$ and female $\left(M_{-} F_{-}\right)$lines (Yamasaki et al. 2000). Expression patterns of CsETR2 and CsERS genes are both similar to that of the ACC synthasecoding gene CsACS2. Neither co-segregation nor additional copies of these genes have been found in any studied genotypes. The functions of CsETR1, CsETR2, and CsERS are suggested by the observation of significant increases in the mRNA accumulation of these deactivated; transduction of the signal activates the ethylene response and leads to the production of female flowers. b Insufficient or absent levels of ethylene cause suppression of the signaling cascade by constitutive activation of CTR proteins and inhibition of downstream signaling. This results in the formation of male or hermaphroditic flowers

genes in the shoot apex of female flower-bearing plants of female $\left(M_{-} F_{-}\right)$and monoecious $\left(M \_f f\right)$ lines in response to ethylene (Yamasaki et al. 2000). In contrast, no significant changes in their expression have been observed in androecious plants ( $m m f f$ ) (Yamasaki et al. 2001). The expression of CSETRI is stamenspecific downregulated in female floral buds. CsAP3, a B-class MADS-box gene with an equivalent function in organ identity determination, is required for the stamenspecific regulation of CsETR1 expression in female flower development, as it can bind and activate the CsETR1 promoter (Sun et al. 2016). CsAP3 expression is decreased in flowers at higher nodes, which is consistent with the expression pattern of CsETR1.

Ethylene perception initiates signal transduction. The binding of ethylene to its receptors leads to the inactivation of CTR1, a constitutively active Raf-like kinase that is a negative regulator of the ethylene response pathway (Kieber et al. 1993). The activity of CTR1 kinase relies on the formation of a complex with the 
ethylene receptors; if a receptor level decreased, the level of active CTR1 decreases as well, leading in turn to an increase in the ethylene response (Wang et al. 2010). Deactivation of the CTR1 complex allows a positive signal to be conveyed from EIN2 to an EIN3 (ethylene-insensitive3 like) family of transcription factors, which are positive regulators of the ethylene signaling pathway. EIN3 promotes the transcription of CSERF1 and other EREBP (ethylene-response-element-binding protein) genes. These genes in turn can interact with the promoters of target genes, which are inducible by ethylene, and activate an ethylene response (Wang et al. 2002). In the absence of ethylene, the CTR1 complex remains active and, by inhibition of EIN2, suppresses the ethylene signaling pathway.

The ethylene signal and ETHYLENE-INSENSTIVE3 (EIN3) and EIN3-LIKE (EIL) gene families are key components in the ethylene signaling pathway. The investigation of Liu et al. (2008) revealed the existence of point mutations in CSEIL between analyzed cucumber lines of different sexes (Liu et al. 2008). The authors observed that the $M$ locus co-segregates with an EIN3 $(E I L)$ in segregating population and its expression increased during floral development and maturation in both male and female flowers. These results suggest that CsEIN3 is involved in floral development via a still-tobe determined mechanism (Bie et al. 2013).

One of the ethylene receptor genes, CsERF025, was identified in a study devoted to fruit bending in cucumber. Overexpression of this gene was able to increase ethylene production and upregulate the expressions of the ethylene synthesis-related genes $A C S$ and $A C O$ (Wang et al. 2017), which could also influence flower sex.

Using yeast one-hybrid and ChIP-PCR assays, it was proven that ethylene signaling induces receptor CSERF110 in the nucleus after which CsERF110 binds to the CsACS11 promoter and activates transcription. Basing on these results on the gynoecious lines (with $F$ ), the authors concluded that CsACS1G and CsACS2 might therefore induce CsACS11. From the melon study, this hypothesis does not explain how expression of CsACS11 is activated in female floral buds in monoecious cucumber plants because they possess recessive $f$. Thus, CsACS11 could have other regulation mechanisms besides ethylene signaling. Upregulation of CsACS11 subsequently produces more endogenous ethylene in developing floral buds, affecting downstream genes involved in sex determination (Tao et al. 2018).
The biochemical experiments using yeast one-hybrid assay demonstrated that another ethylene response factor CsERF31 (Ethylene Response Factor taking part in ethylene signaling pathway) could directly bind the promoter of $M$ and promote its expression. Thus, CsERF31 responded to the ethylene signal derived from $F$-CSACS1 and could mediate the positive feedback regulation of ethylene by activating $M$ expression, which offers an extended "one-hormone hypothesis" of sex differentiation in cucumber (Pan et al. 2018).

Environmental and hormonal factors influencing sex determination in cucumber

The sex determination system in cucumber is very labile because of its susceptibility to external conditions. Factors such as day length, light intensity, temperature, and hormones modulate the sex of a plant and change its floral sex distribution pattern. Long days and high temperatures stimulate the formation of male flowers, while female flowers are produced under short day and lowtemperature conditions (Malepszy and NiemirowiczSzczytt 1991). The combination of light and temperature, specifically the ratio of radiant to thermal energy (photothermal ratio; PTR), also has an influence on sex phenotype. High PTR is correlated with an increased number of female nodes relative to male nodes (Wang et al. 2014). A study on photoperiod revealed that female flower production, and thus cucumber productivity, is cultivar-dependent because of sex differences in flowers produced (Ikram et al. 2017).

Seasonal changes, which are an integration of temperature and photoperiod factor, affect cucumber sex expression with different degrees of influence on flower formation. In the study of Lai et al. (2018), the results indicated that the photoperiod treatment preferentially and significantly influenced flower development processes, while temperature treatment produced stronger responses from phytohormone-pathway-related sex genes (Lai et al. 2018) and DNA methylation has been proven to play a role in this process (Lai et al. 2017).

Various studies have demonstrated that low temperature induces the formation of female flowers (PerlTreves 1999; Miao et al. 2011a). Research on Benincasa hispida, a monoecious plant with the first flowering phase comprising staminate flowers on the main stem (similar to cucumber), has confirmed that the induction of femaleness by lower temperatures $\left(15^{\circ} \mathrm{C}\right.$ during the day and $10^{\circ} \mathrm{C}$ at night) is related to an increase in auxin 
and abscisic acid (ABA) contents of shoot apices (Song et al. 2012). Sugar accumulation also contributes indirectly to the effect of low temperature on female flower formation (Miao et al. 2011a).

To elucidate the mechanism of temperaturedependent sex determination (TSD) in cucumbers, genome-wide alterations in DNA methylation were characterized at the single-base level in apical shoots under different temperature conditions; the transcriptome and sRNA expression profiles were also investigated. The authors of that study proposed that CsACO3 and the AP2/ERF protein are epiregulated in response to temperature changes and thus might participate in the cucumber TSD process. Under lowtemperature conditions, the up-epiregulation of CsACO3 enhances ethylene production, whereas the down-epiregulation of AP2/ERF enhances ethylene signal transduction (Lai et al. 2017). Notably, RAP2.4, a homolog of AP2/ERF, is a negative factor in Arabidopsis for ethylene function (Lin et al. 2008). In a study of Lai et al. (2017), a differentially methylated region in the promoter of CsACO3 (Csa6M421630) showed a fourfold increase in expression after lowtemperature treatment and decreased methylation levels, causing an increase in ACO enzyme activity that could probably arrest anther development.

Miao et al. (2011a) have shown that enhancement of cucumber femaleness can be induced by elevated levels of glucose and sucrose in shoot apices through a sugarsignaling pathway involving hexokinase, an important sugar sensor. Moreover, a complex interaction exists between sugar and hormonal signaling pathways (León and Sheen 2003). ABA and ethylene are two major hormones closely involved in sugar signaling (León and Sheen 2003; Rolland et al. 2006). In many cases, a positive interaction exists between sugar and ABA signaling and an antagonistic relationship between sugar and ethylene signaling (Hanson and Smeekens 2009). A connection between sugar metabolism and the flower sex has been confirmed by the research of Terefe and Tatlioglu (2005). In that study, a strong accumulation of a nucleotide sugar epimerase was observed in male flowers compared with female and hermaphroditic ones. The function of sugars in flower morphogenesis is still unknown.

The one hormone hypothesis in regard to the mechanism of sex determination in cucumber was proposed by Yin and Quinn (1995). This model assumes that one hormone has male and female cell receptors to inhibit one sex and induce the other independently. The results demonstrated that gibberellins (GA) can have dual effects on sex expression in cucumber, inhibiting femaleness and inducing maleness. The dual effects are proposed in the one-hormone model, but in an opposite fashion; the ethylene release agent induced femaleness and inhibited maleness (Yin and Quinn 1995).

The studies performed in order to prove the onehormone model revealed the predominant role of ethylene over other phytohormones during sex determination in cucumber and had been confirmed by several studies. Nevertheless, other chemical substances and growth regulators, such as auxins and brassinosteroids, are also directly or indirectly involved in floral sexual development (Rudich et al. 1972; Trebitsh et al. 1987; Wu et al. 2010; Yin and Quinn 1995; Zhang et al. 2014a). Treatment with auxin or gaseous ethylene, ethephon, or ethrel (all ethylene-releasing substances from plant tissues) induces the development of female flowers (Rudich et al. 1972). The application of exogenous brassinosteroids also increases femaleness in cucumber and causes increased ethylene production (Papadopoulou and Grumet 2005). In contrast, GA induce masculinity, whereas application of AVG (an ethylene biosynthesis inhibitor) or $\mathrm{AgNO}_{3}$ (an ethylene action inhibitor) converts female plants to male ones (Malepszy and Niemirowicz-Szczytt 1991; Yin and Quinn 1995). A high auxin (IAA) level is associated with a female tendency, and exogenous auxin treatment enhances the femaleness of cucumber plants (Rudich et al. 1972). This growth regulator affects sex determination in cucumber rather indirectly, however, by regulation of ethylene production. Trebitsh et al. (1987) have shown that exogenous IAA can increase the expression of ACS genes and promote ACC and ethylene production, thereby affecting female flower formation. Auxininducible genes such as CSIAA2 have been suggested to play a role in the promotion of ethylene and, therefore, in the regulation of cucumber sex (Wu et al. 2010). Nevertheless, the connection between endogenous auxin levels and promotion of femaleness is still not fully understood.

The application of brassinosteroids (BRs), another type of phytohormone, influences cucumber flowering time and increases the number of female flowers. BRs also increase ethylene production and indirectly take part in cucumber sex determination through induction of ethylene biosynthesis (Papadopoulou and Grumet 2005; Wu et al. 2010). A genome-wide analysis allowed 
the identification and characterization of a gene described as CSPSTK1, presumably correlated with female flower formation. CSPSTK1 encodes a putative serine/ threonine kinase involved in several processes, including flower morphogenesis, cell proliferation, and PCD. A correlation exists between BAK1, a receptor in the BR signaling pathway, and CsPSTK1, which suggests the involvement of CSPSTK1 in BR signaling (Pawełkowicz et al. 2012).

Treatment of cucumber plants with exogenous GA inhibits ethylene biosynthesis by suppressing the expression of the CSACS1G gene (Yin and Quinn 1995), which leads to inhibition of female flower production and the promotion of maleness. Several studies involving different plant species have confirmed that regulation of staminate development can be influenced via the GA signaling pathway (Aya et al. 2009; Cheng et al. 2004; Fleet and Sun 2005; Sun 2010, 2011). Zhang et al. (2014a) have identified the cucumber CSGAMYB1 gene as an ortholog of $G A M Y B$, a positive regulator of the GA signaling pathway. Although application of GA can inhibit ethylene synthesis, CsGAMYB1 may regulate cucumber sex expression in an ethylene-independent manner. CSGAMYB1 presumably promotes male flower development and inhibits the formation of female flowers. Sex regulation by ethylene and modulation of sex expression by the transcriptional regulation of CsGAMYB1 may be two independent events; however, crosstalk between these pathways cannot be excluded (Zhang et al. 2014a, 2017). Another regulator of the GA signaling pathway has been found and described: the DELLA homolog $C S G A I P$, suggested to play the role of a negative regulator on GA action (Zhang et al. 2014b). This gene may repress male flower formation by inhibition of B-class floral homeotic genes. The application of exogenous GA, however, promotes proteolysis of CsGAIP through the ubiquitin-proteasome pathway, causing the abolition of transcriptional repression of B-class floral homeotic genes and, as a result, promotion of staminate development (Zhang et al. 2014b). Zhang et al. (2014b) have also shown that another cucumber DELLA homolog, CsGAI2, displays an expression pattern similar to that of $C s G A I P$ and is predominantly expressed in the stems and male flower buds as well. A novel finding of the latest study by these authors is that $C A G 2$, an AG homolog in cucumber, is downregulated upon GA treatment. Previous studies have shown that $C A G 2$ transcripts are not mediated by ethylene; consequently, GA probably suppresses pistil development by inhibiting CAG2 expression, thereby allowing male flowers to develop. Ethylene is not involved in this process (Zhang et al. 2017).

There is also evidence that ABA could be involved in the sex determination process. qPCR analysis has revealed the differential expression of $C S A B I 1$ and $C s A B I 2$ genes (members of the protein phosphatase $2 \mathrm{C}$ gene family) in male and female floral buds. This result indicates that ABA signaling is somehow involved in male and female flower formation and suggests a regulatory role during floral morphogenesis and its function in the selective development of specific whorls in unisexual flowers (Pawełkowicz et al. 2016c).

Genes correlated with floral morphogenesis

Sex expression in cucumber has been extensively studied. To elucidate the sex determination process and underlying molecular mechanisms, the next-generation sequencing (NGS) technology has also been applied. Genome-wide mapping has recently revealed copy number variation involving four genes that define the $F$ locus (Zhang et al. 2015). A 30.2-kb duplicated region was found to be significantly associated with gynoecious plants compared with monoecious ones. A resequencing study of gynoecious and monoecious plants confirmed the loss of the duplicated region from monoecious plants. The duplicated region in gynoecious plants contains ACS1 (CsaG496450), an MYB transcription factor (CsaG496460), a branched-chain amino acid aminotransferase (CsaG496470), and a gene of unknown function (CsaG496450) (Zhang et al. 2015).

Guo et al. (2010) also conducted transcriptome sequencing and comparative analysis of cucumber flower buds with different sex types. They used cucumber flower buds of two near-isogenic lines: one gynoecious and the other hermaphroditic. The authors identified 214 differentially expressed genes (DEGs), of which 90 and 124 displayed higher expression in gynoecious and hermaphroditic lines, respectively. These differences were connected to genes encoding transcription factors, such as zinc finger protein, Aux/IAA connected with auxins, BZR1BES1 involved in the BR cascade, MYC protein, BEL1like homeodomain protein, bHLH protein, WRKY DNAbinding protein, and NAC domain protein. Overrepresented genes in both genotypes included those in the Gene Ontology (GO) categories of biopolymer metabolic process, cellular biopolymer metabolic process, cellular macromolecule metabolic process, and primary metabolic process. Genes differentially expressed between female and 
hermaphrodite genotypes were mostly members of the same GO categories, thus indicating that identical biological processes might require different sets of genes during female and bisexual flower development. In gynoecious plants, the enrichment of GO terms related to responses to different abiotic/biotic stresses and translation has been observed. Hermaphroditic-line-specific categories were proteolysis, chromatin, and chromosome organization (Guo et al. 2010). The two types of floral sex distributions in cucumber gynoecious vs. monoecious have also been investigated in order to isolate genes involved in sex determination. Transcriptome profiling analysis by $\mathrm{Wu}$ et al. (2010) revealed numerous changes in gene expression in genes belonging to ontology groups such as biogenesis, transport and organization of cellular component, macromolecular and cellular biosynthesis, localization, translation, and other processes. The results of this study uncovered many genes (e.g., ACS, Asr1, CsIAA2, CS$A U X 1$, and $T L P$ ) and transcription factors (e.g., EREBP9) involved in plant hormone signaling pathways, which indicates that these genes may play an important role in sex determination.Recently, based on high-throughput RNAseq analysis from the shoot apex derived from cucumber lines of different sex types (females, males, and hermaphrodites), 310 DEGs were identified and new sex-related model of molecular networks (PPI) was described. This contains processes such as hormones, lipid, and sugar metabolism; processes related to cell wall, membrane, and cytoskeleton modifications; ion homeostasis which appears to be important for ethylene perception and signaling; and genes expression mediated by transcription factors related to floral organ identities (Pawełkowicz et al. 2019).

RNA-seq was used to perform the expression of genes between gynoecious and weak female lines at three growth stages. There were many enriched DEGs but nine of them $\left(C s-M C M 6^{*}, C s-A C T 3, C s-X R C C 4, C s-M C M 2^{*}, C s-\right.$ CDC45*,Cs-Dpri*, Cs-H2B,Cs-CDC20*, and Cs$C N G C 1)$ were identified as candidate genes correlated with sex expression. Among these genes, five (marked with*) are involved in the cell cycle pathway, suggesting that they may play an important role in sex determination in cucumber (Wang et al. 2019).

Transcriptome sequencing was used to study the mechanism of pollen abortion. The RNA was isolated from male flower buds from genetic male sterile (GMS) cucumber and fertile wild-type (WT) line. The differentially expressed genes were involved in sporopollenin biosynthetic pathway, cell cycle, DNA damage, and ethylene signaling pathway. It is not clear which genes are responsible for abnormal stamen development, and as suggested, further studies based on gene silencing are needed (Han et al. 2018).

The application of the NGS technology to study subgynoecy in cucumber has been reported by $\mathrm{Bu}$ et al. (2016), who identified quantitative trait loci (QTLs) by simple sequence repeat- and sequencing-based analyses. Genetic analysis of $\mathrm{F}_{2}$ and $\mathrm{BC}_{1}$ populations developed from subgynoecious and monoecious lines revealed the previously suggested quantitative nature of subgynoecy. Three QTLs were identified, one of which, sg3.1, was confirmed by sequencing of parental lines and bulks constructed from the $\mathrm{BC}_{6}$ population. Using PCR-based markers developed from SNP profiling, $\mathrm{sg} 3.1$ was delimited to a 799-kb genomic region (Bu et al. 2016).

The study of sex expression in cucumber has established the role of MADS-box genes in cucumber floral morphogenesis. Analysis of homeotic mutants has revealed that MADS-box genes are not sex-determining, but instead likely act as regulators of the processes leading to the development of a definite sex (Kater et al. 2001). Numerous genes are involved in floral formation. In the study of genes participating in ethylene response, 20 ethylene-responsive genes were found to be induced in the apices of cucumber seedlings by ethephon treatment (Ando et al. 2001a). Genes designated as ERAF16 (similar to S-adenosyl-L-methionine:salicylic acid carboxyl methyltransferase) and ERAF17 (similar to CUS3 from embryogenic callus belonging to the MADS-box gene family) have been found to be involved in female flower formation (Ando et al. 2001a, b; Ando and Sakai 2002).

It was demonstrated that cucumber MADS-box (CUM1) is the homolog of AGAMOUS type c MADS-box gene and shows specific expression in the stamens and carpels (Perl-Treves et al. 1998). In the study of $\mathrm{Gu}$ et al. (2018), the authors detected the expression patterns of CUM1 by in situ hybridization, and it was demonstrated by yeast one-hybrid assay that both the promoter and second intron of CUM1 are required for driving stamen- and carpel-specific expression of CUM1. A yeast one-hybrid assay indicated that the auxin response factors $C s A R F 13$ and $C s A R F 17$ act as the upstream regulators by binding to the second intron of CUM1 (Gu et al. 2018).

In another study, comparing RNA-seq data, the expression of CSAP3 and other Mads-box gene CSPI (Bclass MADS-box gene ortholog of PISTILLATA in Arabidopsis) was suppressed in female line comparing 
to male and hermaphrodite lines, while the CSSUP (putative ortholog of SUPERMAN/FLO10 in Arabidopsis) expression increased. The authors speculate that CSSUP act as regulators that stimulate and suppress a CsAP3 transcription (Pan et al. 2018).

Yamasaki and Kazuto (2009) studied Cs 1-MMP, which encodes a putative matrix metalloproteinase connected with PCD. In male cucumber flowers, the strongest expression was detected in sepals and in the area where pistil primordia were arrested. In female flowers, the highest expression was observed in sepals and in the area of stamen primordial arrest. These results suggest that Cs1-MMP plays an important role in PCD-mediated arrest of sexual organs in flowers (Yamasaki and Kazuto 2009). Several techniques have been used to identify genes correlated with sex determination in cucumber; these include AFLP (Witkowicz et al. 2003) as well as RAPD and subtraction (DSC) techniques (Przybecki et al. 2003, 2004) performed on genomes of near-isogenic lines of different sex types. Differential hybridization (DH) and subtraction (cDNA-DSC) methods have revealed approximately 1000 cDNA markers connected with sex-specific loci (Przybecki et al. 2003, 2004; Pawełkowicz et al. 2017a).

A transcriptome study of 1-2-mm-long floral buds was also undertaken using near-isogenic lines. The isolation of EST fragments connected with chaperonins, ubiquitins, BRs, bZIP transcription factors, glycine, and proline-rich proteins related to floral bud development suggests that these genes participate in the complicated process of sex determination (Pawełkowicz et al. 2015; Przybecki et al. 2003). Detailed expression analysis using in situ RT-PCR or qPCR of whole buds correlated the identified genes with sex organ identity, both in regard to the promotion and inhibition of growth (Przybecki et al. 2003). For example, genes involved in the ubiquitination pathway were differentially expressed between developing male and female cucumber floral buds. This differential expression was confirmed by the qRT-PCR technique and sequencing of several EST clones: CsB10dhB2_1 from the gene encoding ubiquitinconjugating enzyme 32, CsB10dhB2_42 from a gene encoding a chromatin assembly factor with ubiquitin domains, and CsB10dhB2_364 from a gene for ubiquitin hydrolase. $\mathrm{qPCR}^{-}$analysis of
RNA isolated from sex organ primordia of buds by laser capture microdissection (LCM) revealed that gene expression between stamens and carpels is highly differentiated. The idea that ubiquitins participate in sex differentiation by influencing PCD or the ethylene signaling cascade seems to be reasonable (Pawełkowicz et al. 2016b). Another differentially expressed EST from DH libraries was CsB10dhB2_28, a clone of a putative negative transcriptional corepressor gene coding DR1 (down regulation 1) protein which is also putative histone-like transcription factor (Ho et al. 2016) and may be correlated with regulation of flowering time (Pawełkowicz et al. 2017b). Loss of H2A.Z from the chromatin of a piel mutant has been found to result in reduced FLC (flowering locus) expression and premature flowering, which indicates that this histone variant is required for high-level expression of FLC (Deal et al. 2007). The CsB10dhB2_70 clone is homologous to the $C s L B P-1$ (lipid binding protein) gene that encodes a multifunctional protein mainly involved in lipid binding; it, thus, may be involved in the early phase of microspore formation in the tapetum during stamen formation (Pawełkowicz et al. 2017b). CsB10dhB2_178 corresponds to the Cs 4 Srp 40 gene encoding the $40 \mathrm{~S}$ ribosomal protein S4 and is related to stress proteins and tRNA synthase. The overall mechanism of floral morphogenesis in cucumber is quite complicated, and none of the above proteins are obviously connected with sex determination; however, the above-described sequences exhibited clearly visible expression differences in whole cucumber floral buds of different sexes. The application of LCM techniques to specific floral whorls confirmed these expression differences (Pawełkowicz et al. 2017b).

A triparental mapping strategy and the use of microsatellite markers allowed the identification of $m-1$, a novel polymorphic allele of the monoecious locus, promoting bisexual flower formation. The associated 14-bp deletion in the third exon of the CsACS2 gene resulted in a truncated loss-offunction CsACS2 protein (Tan et al. 2015). Win et al. (2015) have developed an $F$ locus-specific co-dominant marker useful for distinguishing homo- and heterozygous gynoecious individuals. According to the authors, this marker should allow 
faster and more efficient selection of cucumber breeding lines (Win et al. 2015).

Integrated analysis of multiple biparental mapping populations has identified CSCLAVATA 3 (CsCLV3) as a single gene underlying carpel number variation in cucumber ( $\mathrm{Li}$ et al. 2016a). Carpel number, an important cucumber fruit quality trait because of its association with fruit shape, size, and weight, varies from two to seven in cucumber germplasm collections. The CLV pathway for regulating meristem size is also correlated with carpel number in cucumber ( $\mathrm{Li}$ et al. 2016a).

miRNAs and sex determination

By suggesting that miRNAs play a role in unisexual flower development, Sun et al. (2010) provided a new insight into sex determination in cucumber. The "miRNA initiative" hypothesis, which explains why ethylene is involved in the selective promotion of female flowers, assumes that the formation of different cucumber sex types has arisen by adaptation to environmental changes. Unisexual cucumber flowers presumably arose from hermaphroditic ancestors (Barrett 2010). Changing environmental conditions altered miRNA expressions, which increased the levels of TCP transcription factors involved in the regulation of plant growth and development (or other miRNA target genes) and in turn caused inhibition of ovary development. As a result of these alterations, which were likely sporadic events occurring only in a few floral buds, andromonoecious cucumber plants were generated (Sun et al. 2010). This type of plant adaptation to changing conditions thus created opportunities for cross-pollination. To overcome the problem of reduced numbers of offspring due to ovary inhibition, the $M$ gene diverged, resulting in monoecious plants. An $F$ gene duplication event (Knopf and Trebitsh 2006) provided additional copies of CsACS1G and led to the gynoecious genotype, resulting in an increased number of offspring and cross-pollination (Sun et al. 2010).

Zhang et al. 2018 performed a series of wholegenome small RNA, degradome and transcriptome analyses on cucumber shoot apical tissues treated with different regimes of temperature and photoperiod. A total of 164 known miRNAs derived from 68 families and 203 novel miRNAs from 182 families were identified. In that study, the authors found a solid example of a new miRNA (novelmir153) that originated from an intron, and additionally, it was found to target 2087 mRNAs by prediction and has 232 targets proven by degradome analysis, accounting for 45.26-58.88\% of the total miRNA targets in this plant. The expressional profiling showed that some of the miRNAs were primarily affected by temperature rather than by photoperiod (Zhang et al. 2018).

\section{Comprehensive model of the cucumber gene network controlling sex determination}

Cucumber is widely considered to be an excellent model for the study of sex determination in monoecious plants. The results of extensive physiological and genetic studies conducted in cucumber, a wide range of available sex phenotypes and genotypes (six different sex types), and a published genome sequence provide very good resources for research on sex determination. Sex expression in cucumber plants is very labile, because many factors, including light, temperature, exogenous substances, and hormones, have an impact on the process of determination. Susceptibility to changes in sex under the influence of external factors may be useful in scientific research and plant breeding, for example, for obtaining a desired sex type.

The ability to control and harness plant reproduction for human needs is becoming a reality as information on gender differences increases. Although the mechanisms described in this paper concern sex expression in cucumber, these findings can also be applied to modify the attributes of other economically important species. New possibilities for breeding in agriculture and horticulture as a consequence of this knowledge include the following: control of flower sex type development; more efficient seed multiplication; modification of floral architecture; development of new markers for plant breeding; the creation of new varieties for horticultural, agricultural, and forestry uses; more efficient food production; the generation of varieties with new features (e.g., for production of biomass for the biofuels industry); and control of blooming time (which can contribute to adaptation to different climatic conditions and crop cultivation areas).

In this review, we have summarized the results of studies aimed at unraveling the main aspects of plant sex 
determination. Here, we offer a new model providing a new perspective on sex determination in cucumber. Studies thus far have focused on the involvement of $F, M$, and $A$ genes in sex expression. Our model for cucumber sex determination assumes the involvement of the $G y$ gene and possibly other related genes (Fig. 4). Genes encoding ACC synthases $(F, M$, and $A)$ and ACC oxidases participate in sex determination in cucumber by regulating ethylene biosynthesis. Various findings suggest that the $G y$ gene is also indirectly engaged in this process - by regulation of CSPSTK1 gene expression and inhibition of the CsACO2 gene - and can also influence ACS genes (assuming that the melon model involving the CmWIP and CmACS11 genes, is applicable in cucumber). In the presence of ethylene, CTR is deactivated; transduction of this signal activates the ethylene response (Fig. 4a), with female flowers produced as a result. Insufficient levels or the absence of ethylene causes suppression of the signaling cascade by constitutive activation of CTR proteins and inhibition of downstream signaling (Fig. 4b). This results in the formation of male or hermaphroditic flowers. Phytohormones can also trigger ethylene biosynthesis and perception. Gibberellins promote maleness by inhibiting the expression of CsACS1G and probably suppress pistil development by inhibiting CAG2 expression, thereby allowing male flowers to develop; ethylene is not involved in this process. Auxins and brassinosteroids have positive influences on the expressions of genes (e.g., CsACS1G and $C s-I A A 2)$ that induce ethylene production and promote femaleness. In contrast, ABA suppresses the deactivation of the CTR1 protein and transduction of the ethylene signal; male flowers thus occur. Suppression via ABA is also caused by low temperature and sugar signaling. In addition, epiregulation of methylome changes associated with low temperatures can upregulate $\mathrm{Cs} A C O 3$ and downregulate $A P 2 / E R F$ (RAP2.4) causing female flower formation (Fig. 4a). We note that the role of the $G y$ gene is still poorly understood in cucumber. By analogy to the melon model, we propose that Gy triggers CsACS11 expression and thus influences sex determination.

\section{Future prospects}

The identification of genes determining the process of sexual development is of great interest to both researchers and breeders. Many genes related to sex expression in cucumber have currently been identified, and ethylene plays a major role in the process of sex determination. Although the underlying genetics and phytohormonal and environmental factors affecting sex expression in cucumber are well characterized, the molecular aspects of cucumber sex determination are still obscure; this creates many opportunities for further research.

NGS, TILLING, and reverse and forward genetics strategies are currently being applied to elucidate the genetic regulation of sex determination in cucumber. In the future, more precise approaches should be undertaken to investigate the global network of molecules involved in this process. Genes as well as their interactions need to be investigated on different omics levels. Epigenetics studies and regulome and degradome analyses, such as proteome and metabolome surveys, should then be performed to clarify and elucidate the mechanism(s) of sex determination in cucumber.

Acknowledgements The authors would like to thank Michał Wojcieszek, MSc, for his help in photographing of plants. We thank Barbara Goodson, PhD, from Edanz Group (www. edanzediting.com/ac) for editing the English text of this manuscript.

Funding information This study was supported by a grant from the National Science Center, Poland (No. 2011/01/B/NZ2/ 01631).

Open Access This article is distributed under the terms of the Creative Commons Attribution 4.0 International License (http:// creativecommons.org/licenses/by/4.0/), which permits unrestricted use, distribution, and reproduction in any medium, provided you give appropriate credit to the original author(s) and the source, provide a link to the Creative Commons license, and indicate if changes were made.

\section{References}

Adams DO, Yang SF (1979) Ethylene biosynthesis: identification of 1-aminocyclopropane-1-carboxylic acid as an intermediate in the conversion of methionine to ethylene. Proc Natl Acad U S A 76:170-176

Ainsworth CC, Lu J, Winfield M, Parker JS (1999) Sex determination by X: autosome dosage: Rumex acetosa (sorrel). In: Ainsworth CC (ed) Sex determination in plants. BIOS Scientific Publishers Ltd, Oxford, pp 121-136

Ando S, Sakai S (2002) Isolation of an ethylene-responsive gene (ERAF16) for a putative methyltransferase and correlation of ERAF16 gene expression with female flower formation in cucumber plants (Cucumis sativus). Physiol Plant 116:213222

Ando S, Sato Y, Sakai S (2001a) Cloning of ethylene responsive genes from the apices of cucumber plants (Cucumis sativus L.). Plant Biotechnol 18:163-167 
Ando S, Sato Y, Kamachi S, Sakai S (2001b) Isolation of a MADS-box gene (ERAF17) and correlation of its expression with the induction of formation of female flowers by ethylene in cucumber plants (Cucumis sativus L.). Planta 213:943952

Aryal R, Jagadeeswaran G, Zheng Y, Yu Q, Sunkar R, Ming R (2014) Sex specific expression and distribution of small RNAs in papaya. BMC Genomics 15:20

Aya K, Ueguchi-Tanaka M, Kondo M, Hamada K, Yano K, Nishimura M, Matsuoka M (2009) Gibberellin modulates anther development in rice via the transcriptional regulation of GAMYB. Plant Cell 21:1453-1472

Bai SL, Peng YB, Cui JX, Gu HT, Xu LY, Li YQ, Xu ZH, Bai SN (2004) Developmental analyses reveal early arrests of the spore-bearing parts of reproductive organs in unisexual flowers of cucumber (Cucumis sativus L.). Planta 220:230240

Banks JA (2008) MicroRNA, sex determination and floral meristem determinacy in maize. Genome Biol 9:204

Barrett SCH (2010) Understanding plant reproductive diversity. Phil Trans R Soc B Biol Sci 365:99-109

Bartlett ME, Thompson B (2014) Meristem identity and phyllotaxis in inflorescence development. Front Plant Sci 5:508

Bartlett M, Thompson B, Brabazon H, Del Gizzi R, Zhang T, Whipple C (2016) Evolutionary dynamics of floral homeotic transcription factor protein-protein interactions. Mol Biol Evol 33:1486-1501

Bie BB, Pan JS, He HL, Yang XQ, Zhao JL, Cai R (2013) Molecular cloning and expression analysis of the ethylene insensitive3 (EIN3) gene in cucumber (Cucumis sativus). Genet Mol Res 12:4179-4191

Boualem A, Fergany M, Fernandez R, Troadec C, Martin A, Morin H, Sari MA, Collin F, Flowers JM, Pitrat M, Purugganan MD, Dogimont C, Bendahmane A (2008) A conserved mutation in an ethylene biosynthesis enzyme leads to andromonoecy in melons. Science 321:836-838

Boualem A, Troadec C, Kovalski I, Sari MA, Perl-Treves R, Bendahmane A (2009) A conserved ethylene biosynthesis enzyme leads to andromonoecy in two Cucumis species. PLoS One 4:e6144

Boualem A, Troadec C, Camps C, Lemhemdi A, Morin H, Sari MA, Fraenkel-Zagouri R, Kovalski I, Dogimont C, PerlTreves R, Bendahmane A (2015) A cucurbit androecy gene reveals how unisexual flowers develop and dioecy emerges. Science 350:688-691

Boualem A, Lemhemdi A, Sari MA et al (2016) The andromonoecious sex determination gene predates the separation of Cucumis and Citrullus genera. PloS One 11: e0155444

Bowman JL, Smyth DR, Meyerowitz EM (2012) The ABC model of flower development: then and now. Development 139: 4095-4098

Bracale M, Caporali E, Galli MG, Longo C, Marziani-Longo G, Rossi G, Spada A, Soave C, Falavigna A, Raffaldi F, Maestri E, Restivo FM, Tassi F (1991) Sex determination and differentiation in Asparagus officinalis L. Plant Sci 80:67-77

Bu F, Chen H, Shi Q, Zhou Q, Gao D, Zhang Z, Huang S (2016) A major quantitative trait locus conferring subgynoecy in cucumber. Theor Appl Genet 129:97-104
Calderon-Urrea A, Dellaporta SL (1999) Cell death and cell protection genes determine the fate of pistils in maize. Development 126:435-441

Cavagnaro PF, Senalik DA, Yang L, Simon PW, Harkins TT, Kodira CD, Huang S, Weng Y (2010) Genome-wide characterization of simple sequence repeats in cucumber (Cucumis sativus L.). BMC Genomics 11:569

Chen YH, Fu XM, Wu H, Zang J (2012) CsACO4, an ACC oxidase gene regulating male differentiation in cucumber. Afr J Biotechnol 11:13069-13074

Chen H, Sun J, Li S, Cui Q, Zhang H, Xin F, Wang H, Lin T, Gao D, Wang S, Li X, Wang D, Zhang Z, Xu Z, Huang S (2016) An ACC oxidase gene essential for cucumber carpel development. Mol Plant 9:1315-1327

Cheng H, Qin L, Lee S, Fu X, Richards DE, Cao D, Luo D, Harberd NP, Peng J (2004) Gibberellin regulates Arabidopsis floral development via suppression of DELLA protein function. Development 131:1055-1064

Chuck G, Meeley R, Irish E, Sakai H, Hake S (2007) The maize tasselseed4 microRNA controls sex determination and meristem cell fate by targeting Tasselseed6/indeterminate spikelet1. Nat Genet 39:1517-1521

Coen ES, Meyerowitz EM (1991) The war of the whorls: genetic interactions controlling flower development. Nature 353:3137

Ćulafić L, Nešković M (1980) Effect of growth substances on flowering and sex expression in isolated apical buds of Spinacia oleracea. Physiol Plant 48:588-591

Deal R, Topp C, McKinney E, Meaghera R (2007) Repression of flowering in Arabidopsis requires activation of FLOWERING LOCUS C expression by the histone variant H2A.Z. Plant Cell 19:74-83

Delorme VG, McCabe PF, Kim DJ, Leaver CJ (2000) A matrix metalloproteinase gene is expressed at the boundary of senescence and programmed cell death in cucumber. Plant Physiol 123:917-927

Durand B, Durand R (1991) Sex determination and reproductive organ differentiation in Mercurialis. Plant Sci 80:49-65

Fleet CM, Sun TP (2005) A DELLAcate balance: the role of gibberellin in plant morphogenesis. Curr Opin Plant Biol 8: $77-85$

Grant S, Houben A, Vyskot B, Siroky J, Pan WH, Macas J, Saedler $\mathrm{H}$ (1994) Genetics of sex determination in flowering plants. Dev Genet 15:214-230

Grumet R, Katzir N, Garcia-Mas J (2017) Genetics and genomics of Cucurbitaceae. Springer Nature, Cham

Gu R, Liu X, Zhao W, Yan S, Sun L, Wu B, Zhang X (2018) Functional characterization of the promoter and second intron of CUM1 during flower development in cucumber (Cucumis sativus L.). Horticult Plant J 4(3):103-110

Guo S, Zheng Y, Joung J-G, Liu S, Zhang Z, Crasta OR, Sobral BW, Xu Y, Huang S, Fei Z (2010) Transcriptome sequencing and comparative analysis of cucumber flowers with different sex types. BMC Genomics 11:384

Guo S, Sun B, Looi LS, Xu Y, Gan ES, Huang J, Ito T (2015) Coordination of flower development through epigenetic regulation in two model species: rice and Arabidopsis. Plant Cell Physiol 56:830-842

Han Y, Wang X, Zhao F et al (2018) Transcriptomic analysis of differentially expressed genes in flower-buds of genetic male 
sterile and wild type cucumber by RNA sequencing. Physiol Mol Biol Plants 24(3):359-367

Hanson J, Smeekens S (2009) Sugar perception and signallingan update. Curr Opin Plant Biol 12:562-567

Hao YJ, Wang DH, Peng YB, Bai SL, Xu LY, Li YQ, Xu ZH, Bai SN (2003) DNA damage in the early primordial anther is closely correlated with stamen arrest in the female flower of cucumber (Cucumis sativus L.). Planta 217:888-895

Ho H, Low JZ, Gudimella R, Tammi MT, Harikrishna JA (2016) Expression patterns of inflorescence- and sex-specific transcripts in male and female inflorescences of African oil palm (Elaeis guineensis). Ann Appl Biol 168:274-289

Hu B, Li D, Liu X, Qi J, Gao D, Zhao S, Huang S, Sun J, Yang L (2017) Engineering non-transgenic gynoecious cucumber using an improved transformation protocol and optimized CRISPR/Cas9 system. Mol Plant 10:1575-1578

Huang S, Li R, Zhang Z, Li L, Gu X, Fan W, Lucas WJ, Wang X, Xie B, Ni P, Ren Y, Zhu H, Li J, Lin K, Jin W, Fei Z, Li G, Staub J, Kilian A, van der Vossen EAG, Wu Y, Guo J, He J, Jia Z, Ren Y, Tian G, Lu Y, Ruan J, Qian W, Wang M, Huang Q, Li B, Xuan Z, Cao J, Asan, Wu Z, Zhang J, Cai Q, Bai Y, Zhao B, Han Y, Li Y, Li X, Wang S, Shi Q, Liu S, Cho WK, Kim JY, Xu Y, Heller-Uszynska K, Miao H, Cheng Z, Zhang S, Wu J, Yang Y, Kang H, Li M, Liang H, Ren X, Shi Z, Wen M, Jian M, Yang H, Zhang G, Yang Z, Chen R, Liu S, Li J, Ma L, Liu H, Zhou Y, Zhao J, Fang X, Li G, Fang L, Li Y, Liu D, Zheng H, Zhang Y, Qin N, Li Z, Yang G, Yang S, Bolund L, Kristiansen K, Zheng H, Li S, Zhang X, Yang H, Wang J, Sun R, Zhang B, Jiang S, Wang J, du Y, Li S (2009) The genome of the cucumber, Cucumis sativus L. Nat Genet 41: 1275-1281

Ikram MMM, Esyanti RR, Dwivany FM (2017) Gene expression analysis related to ethylene induced female flowers of cucumber (Cucumis sativus L.) at different photoperiod. J Plant Biotechnol 44:229-234

Jaligot E, Adler S, Debladis É, Beulé T, Richaud F, Ilbert P, Finnegan EJ, Rival A (2011) Epigenetic imbalance and the floral developmental abnormality of the in vitro-regenerated oil palm Elaeis guineensis. Ann Bot 108:1453-1462

Janoušek B, Široký J, Vyskot B (1996) Epigenetic control of sexual phenotype in a dioecious plant, Melandrium album. Mol Gen Genet 250:483-490

Kahana A, Silberstein L, Kessler N, Goldstein RS, Perl-Treves R (1999) Expression of ACC oxidase genes differs among sex genotypes and sex phases in cucumber. Plant Mol Biol 41: 517-528

Kamachi S, Sekimoto H, Kondo N, Sakai S (1997) Cloning of a cDNA for a 1-aminocyclopropane-1-carboxylate synthase that is expressed during development of female flowers at the apices of Cucumis sativus L. Plant Cell Physiol 38:11971206

Kater MM, Franken J, Carney KJ, Colombo L, Angenent GC (2001) Sex determination in the monoecious species cucumber is confined to specific floral whorls. Plant Cell 13:481493

Kieber JJ, Rothenberg M, Roman G, Feldman KA, Ecker JR (1993) CTR1, a negative regulator of the ethylene response pathway in Arabidopsis, encodes a member of the Raf family of protein kinases. Cell 72:427-441

Knopf RR, Trebitsh T (2006) The female-specific Cs-ACS1G gene of cucumber. A case of gene duplication and recombination between the non-sex-specific 1-aminocyclopropane-1carboxylate synthase gene and a branched-chain amino acid transaminase gene. Plant Cell Physiol 47:1217-1228

Kubicki B (1969a) Investigations on sex determination in cucumbers (Cucumis sativus L.). V. Genes controlling intensity of femaleness. Genet Pol 10:69-86

Kubicki B (1969b) Investigation of sex determination in cucumber (Cucumis sativus L.). VI. Androecism. Genet Pol 10:87-99

Kubicki B (1969c) Investigation of sex determination in cucumber (Cucumis sativus L.). VII Trimonoecism. Genet Pol 10:123143

Kubicki B (1974) New sex types in cucumber and their uses in breeding work. Proc XIX Intl Hort Congr 3:475-485

Kumar A, Jaiswal VS (1984) Sex reversal and fruit formation on male plants of Carica Papaya L. by ethrel and chlorflurenol. Proc Plant Sci 9:635-641

Lai YS, Zhang X, Zhang W, Shen D, Wang H, Xia Y, Qiu Y, Song J, Wang C, Li X (2017) The association of changes in DNA methylation with temperature-dependent sex determination in cucumber. J Exp Bot 68:2899-2912

Lai YS, Shen D, Zhang W, Zhang X, Qiu Y, Wang H, Dou X, Li S, Wu Y, Song J, Ji G, Li X (2018) Temperature and photoperiod changes affect cucumber sex expression by different epigenetic regulations. BMC Plant Biol 18:268

Lebel-Hardenack S, Grant SR (1997) Genetics of sex determination in flowering plants. Trends Plant Sci 2:130-136

Lebel-Hardenack S, Ye D, Koutnikova H, Saedler H, Grant SR (1997) Conserved expression of a TASSELSEED2 homolog in the tapetum of the dioecious Silene latifolia and Arabidopsis thaliana. Plant J 12:515-526

Lee JH, Kim YC, Choi D, Han JH, Jung Y, Lee S (2018) RNA expression, protein activity, and interactions in the ACC synthase gene family in cucumber (Cucumis sativus L.). Hortic Environ Biotechnol 59:81-91

León P, Sheen J (2003) Sugar and hormone connections. Trends Plant Sci 8:110-116

Li Z, Huang S, Liu S, Pan J, Zhang Z, Tao Q, Shi Q, Jia Z, Zhang W, Chen H, Si L, Zhu L, Cai R (2009) Molecular isolation of the $M$ gene suggests that a conserved-residue conversion induces the formation of bisexual flowers in cucumber plants. Genetics 182:1381-1385

Li Z, Wang S, Tao Q, Pan J, Si L, Gong Z, Cai R (2012) A putative positive feedback regulation mechanism in CsACS2 expression suggests a modified model for sex determination in cucumber (Cucumis sativus L.). J Exp Bot 63:4475-4484

Li SF, Gao WJ, Zhao XP, Dong TY, Deng CL, Lu LD (2014) Analysis of transposable elements in the genome of Asparagus officinalis from high coverage sequence data. PLoS One 9:e97189

Li ZF, Zhang YC, Chen YQ (2015) miRNAs and lncRNAs in reproductive development. Plant Sci 238:46-52

Li S, Pan Y, Wen C, Li Y, Liu X, Zhang X, Behera TK, Xing G, Weng Y (2016a) Integrated analysis in bi-parental and natural populations reveals CsCLAVATA3 (CsCLV3) underlying carpel number variations in cucumber. Theor Appl Genet 129: $1007-1022$

Li SF, Zhang GJ, Yuan JH, Deng CL, Gao WJ (2016b) Repetitive sequences and epigenetic modification: inseparable partners play important roles in the evolution of plant sex chromosomes. Planta 243:1083-1095 
Lin RC, Park HJ, Wang HY (2008) Role of Arabidopsis RAP2.4 in regulating light- and ethylene-mediated developmental processes and drought stress tolerance. Mol Plant 1:42-57

Liu S, Xu L, Jia Z, Xu Y, Yang Q, Fei Z, Lu X, Chen H, Huang S (2008) Genetic association of ETHYLENE-INSENSITIVE3like sequence with the sex-determining $M$ locus in cucumber (Cucumis sativus L.). Theor Appl Genet 117:927-933

Malepszy S, Niemirowicz-Szczytt K (1991) Sex determination in cucumber (Cucumis sativus) as a model system for molecular biology. Plant Sci 80:39-47

Martin A, Troadec C, Boualem A, Rajab M, Fernandez R, Morin H, Pitrat M, Dogimont C, Bendahmane A (2009) A transposon-induced epigenetic change leads to sex determination in melon. Nature 461:1135-1138

Mathooko FM, Mwaniki MW, Nakatsuka A, Shiomi S, Kubo Y, Inaba A, Nakamura R (1999) Expression characteristics of $C S-A C S 1, C S-A C S 2$ and CS-ACS3, three members of the 1aminocyclopropane-1-carboxylate synthase gene family in cucumber (Cucumis sativus L.) fruit under carbon dioxide stress. Plant Cell Physiol 40:164-172

McKeown M (1994) Sex determination and differentiation. Dev Genet 15:201-204

Miao M, Yang X, Han X, Wang K (2011a) Sugar signalling is involved in the sex expression response of monoecious cucumber to low temperature. J Exp Bot 62:797-804

Miao H, Zhang S, Wang X, Zhang Z, Li M, Mu S, Cheng Z, Zhang R, Huang S, Xie B, Fang Z, Zhang Z, Weng Y, Gu X (2011b) A linkage map of cultivated cucumber (Cucumis sativus L.) with 248 microsatellite marker loci and seven genes for horticulturally important traits. Euphytica 182:167-176

Mibus H, Tatlioglu ĆT (2004) Molecular characterization and isolation of the $F / f$ gene for femaleness in cucumber (Cucumis sativus L.). Theor Appl Genet 109:1669-1676

Muyle A, Zemp N, Deschamps C, Mousset S, Widmer A, Marais GAB (2012) Rapid de novo evolution of X chromosome dosage compensation in Silene latifolia, a plant with young sex chromosomes. PLoS Biol 10:e1001308

Oeller PW, Lu MW, Taylor LP, Pike DA, Theologis A (1991) Reversible inhibition of tomato fruit senescence by antisense RNA. Science 254:437-439

Osipowski P, Wojcieszek M, Pawełkowicz M et al (2016) Progress in assembling the cucumber (Cucumis sativus) Borszczagowski B10 line genome using long single molecule, real-time reads. XIth Eucarpia Cucurbitaceae, Warsaw 24-28.06.2016

Pan J, Wang G, Wen H, Du H, Lian H, He H et al (2018) Differential gene expression caused by the $F$ and $M$ loci provides insight into ethylene-mediated female flower differentiation in cucumber. Front Plant Sci 9:1091

Papadopoulou E, Grumet R (2005) Brassinosteriod-induced femaleness in cucumber and relationship to ethylene production. Hort Sci 40:1763-1767

Pawełkowicz M, Osipowski P, Wojcieszek M et al (2012) Identification and characterization of genes connected with flower morphogenesis in cucumber. BioTechnologia 93:123134

Pawełkowicz M, Skarzyńska A, Posyniak K, Ziąbska K, Pląder W, Przybecki Z (2015) Advantages and disadvantages in usage of bioinformatic programs in promoter region analysis. Proc SPIE 9662:96621L
Pawełkowicz M, Zieliński K, Zielińska D, Pląder W, Yagi K, Wojcieszek M, Siedlecka E, Bartoszewski G, Skarzyńska A, Przybecki Z (2016a) Next generation sequencing and omics in cucumber (Cucumis sativus L.) breeding directed research. Plant Sci 242:77-88

Pawełkowicz ME, Osipowski P, Wojcieszek M, Kowalczuk C, Pląder W, Przybecki Z (2016b) Bioinformatic investigation of the role of ubiquitins in cucumber flower morphogenesis. Proc SPIE 10031:100312Y

Pawełkowicz ME, Wojcieszek M, Osipowski P, Krzywkowski T, Pląder W, Przybecki Z (2016c) Identification and bioinformatics comparison of two novel phosphatases in monoecious and gynoecious cucumber lines. Proc SPIE 10031:100312S

Pawełkowicz ME, Skarzyńska A, Cebula J, Hincha D, Ziąbska K, Pląder W, Przybecki Z (2017a) Bioinformatics and expressional analysis of cDNA clones from floral buds. Proc SPIE 10445:1044538

Pawełkowicz ME, Skarzyńska A, Kowalczuk C, Pląder W, Przybecki Z (2017b) Laser capture microdissection to study flower morphogenesis. Proc SPIE 10445:1044539

Pawełkowicz M, Pryszcz L, Skarzyńska A, Wóycicki RK, Posyniak K, Rymuszka J, Przybecki Z, Pląder W (2019) Comparative transcriptome analysis reveals new molecular pathways for cucumber genes related to sex determination. Plant Reprod 1-24. https://doi.org/10.1007/s00497-01900362-z

Perl-Treves R (1999) Male to female conversion along the cucumber shoot: approaches to studying sex genes and floral development in Cucumis sativus. In: Ainsworth CC (ed) Sex determination in plants. BIOS Scientific Publishers Ltd, Oxford, pp 189-216

Perl-Treves R, Kahana A, Rosenman N, Xiang Y, Silberstein L (1998) Expression of multiple AGAMOUS-like genes in male and female flowers of cucumber (Cucumis sativus L.). Plant Cell Physiol 39:701-710

Piferrer F (2013) Epigenetics of sex determination and gonadogenesis. Dev Dynam 242:360-370

Przybecki Z, Kowalczyk ME, Siedlecka E, Urbanczyk-Wochniak E, Malepszy S (2003) The isolation of cDNA clones from cucumber (Cucumis sativus L.) floral buds coming from plants differing in sex. Cell Mol Biol Lett 8:421-438

Przybecki Z, Kowalczyk ME, Witkowicz J, Filipecki M, Siedlecka E (2004) Polymorphom of sexually different cucumber (Cucumis sativus L.) NIL lines. Cell Mol Biol Lett 9:919933

Renner SS (2014) The relative and absolute frequencies of angiosperm sexual systems: dioecy, monoecy, gynodioecy, and an updated online database. Am J Bot 101:1588-1596

Renner SS (2016) Pathways for making unisexual flowers and unisexual plants: moving beyond the "two mutations linked on one chromosome" model. Am J Bot 103:587-589

Rolland F, Baena-Gonzalez E, Sheen J (2006) Sugar sensing and signalling in plants: conserved and novel mechanisms. Annu Rev Plant Biol 57:675-709

Rudich J (1990) Biochemical aspects of hormonal regulation of sex expression in cucurbits. In: Bates DM, Robinson RW, Jeffary C (eds) Biology and utilization of the Cucurbitaceae. Cornell University of Press, Ithaca, pp 269-280

Rudich J, Halevy AH, Kedar N (1972) Ethylene evolution from cucumber plants as related to sex expression. Plant Physiol 49:998-999 
She X, Xu X, Fedotov A, Kelly WG, Maine EM (2009) Regulation of heterochromatin assembly on unpaired chromosomes during Caenorhabditis elegans meiosis by components of a small RNA-mediated pathway. PLoS Genet 5: e1000624

Shiomi S, Yamamoto M, Ono T, Kakiuchi K, Nakamoto J, Nakatsuka A, Kubo Y, Nakamura R, Inaba A, Imaseki H (1998) cDNA cloning of ACC synthase and ACC oxidase genes in cucumber fruit and their differential expression by wounding and auxin. J Jap Soc Hortic Sci 67:685-692

Song S, Huang H, Liu H, Sun G, Chen R (2012) Low temperature during seedling stage promotes female flower determination but not yield of Chieh-qua. Hortic Environ Biotechnol 53: 343-348

Sun TP (2010) Gibberellin-GID1-DELLA: a pivotal regulatory module for plant growth and development. Plant Physiol 154:567-570

Sun TP (2011) The molecular mechanism and evolution of the GA-GID1-DELLA signalling module in plants. Curr Biol 21: R338-R345

Sun JJ, Li F, Li X, Liu XC, Rao GY, Luo JC, Wang DH, Xu ZH, Bai SN (2010) Why is ethylene involved in selective promotion of female flower development in cucumber? Plant Signal Behav 5:1052-1056

Sun JJ, Li F, Wang DH et al (2016) CsAP3: a cucumber homolog to Arabidopsis APETALA3 with novel characteristics. Front Plant Sci 7:1181

Switzenberg JA, Little HA, Hammar SA, Grumet R (2014) Floral primordia-targeted ACS (1-aminocyclopropane-1-carboxylate synthase) expression in transgenic Cucumis melo implicates fine tuning of ethylene production mediating unisexual flower development. Planta 240:797-808

Tan J, Tao Q, Niu H, Zhang Z, Li D, Gong Z, Weng Y, Li Z (2015) A novel allele of monoecious (m) locus is responsible for elongated fruit shape and perfect flowers in cucumber (Cucumis sativus L.). Theor Appl Genet 128:2483-2493

Tanurdzic M, Banks JA (2004) Sex-determining mechanisms in land plants. Plant Cell 16:61-71

Tao Q, Niu H, Wang Z, Zhang W, Wang H, Wang S, Zhang X, Li Z (2018) Ethylene responsive factor ERF110 mediates ethylene-regulated transcription of a sex determinationrelated orthologous gene in two Cucumis species. J Exp Bot 69:2953-2965

Telgmann-Rauber A, Jamsari A, Kinney MS, Pires JC, Jung C (2007) Genetic and physical maps around the sexdetermining $M$-locus of the dioecious plant asparagus. Mol Gen Genomics 278:221-234

Terefe D (2005) Molecular genetics and physiological studies on the sex-determining $\mathrm{M} / \mathrm{m}$ and $\mathrm{A} / \mathrm{a}$ genes in cucumber (Cucumis sativus L.). Dissertation, Leibniz Universität Hannover

Terefe D, Tatlioglu T (2005) Isolation of a partial sequence of a putative nucleotide sugar epimerase, which may involve in stamen development in cucumber (Cucumis sativus L.). Theor Appl Genet 111:1300-1307

Trebitsh T, Rudich J, Riov J (1987) Auxin, biosynthesis of ethylene and sex expression in cucumber (Cucumis sativus). Plant Growth Regul 5:105-113

Trebitsh T, Staub JE, O’Neill SD (1997) Identification of a 1aminocyclopropane-1-carboxylic acid synthase gene linked to the Female $(F)$ locus that enhances female sex expression in cucumber. Plant Physiol 113:987-995

Vyskot B, Hobza R (2004) Gender in plants: sex chromosomes are emerging from the fog. Trends Genet 20:432-438

Vyskot B, Hobza R (2015) The genomics of plant sex chromosomes. Plant Sci 236:126-135

Wang KL-C, Li H, Ecker JR (2002) Ethylene biosynthesis and signalling networks. Plant Cell 14:S131-S151

Wang DH, Li F, Duan QH, Han T, Xu ZH, Bai SN (2010) Ethylene perception is involved in female cucumber flower development. Plant J 61:862-872

Wang YH, Behera TK, Kole C (2012) Genetics, genomics and breeding of cucurbits. CRC, New York

Wang L, Yang X, Ren Z, Wang X (2014) The co-involvement of light and air temperature in regulation of sex expression in monoecious cucumber (Cucumis sativus L.). Agr Sci 5:858863

Wang C, Xin M, Zhou X, Liu C, Li S, Liu D, Xu Y, Qin Z (2017) The novel ethylene-responsive factor CsERF025 affects the development of fruit bending in cucumber. Plant Mol Biol 95:519-531

Wang R, Lin YE, Jin Q, Yao C, Zhong Y, Wu T (2019) RNA-Seq analysis of gynoecious and weak female cucumber revealing the cell cycle pathway may regulate sex determination in cucumber. Gene 687:289-297

Wils CR, Kaufmann K (2016) Gene-regulatory networks controlling inflorescence and flower development in Arabidopsis thaliana. Biochim Biophys Acta 1860:95-105

Win KT, Zhang C, Song K et al (2015) Development and characterization of a co-dominant molecular marker via sequence analysis of a genomic region containing the Female $(F)$ locus in cucumber (Cucumis sativus L.). Mol Breed 35:1-10

Witkowicz J, Urbańczyk-Wochniak E, Przybecki Z (2003) AFLP marker polymorphism in cucumber (Cucumis sativus $\mathrm{L}$ ) near isogenic lines differing in sex expression. Cell Mol Biol Lett 8:375-381

Wóycicki R, Witkowicz J, Gawroński P, Dąbrowska J, Lomsadze A, Pawełkowicz M, Siedlecka E, Yagi K, Pląder W, Seroczyńska A, Śmiech M, Gutman W, NiemirowiczSzczytt K, Bartoszewski G, Tagashira N, Hoshi Y, Borodovsky M, Karpiński S, Malepszy S, Przybecki Z (2011) The genome sequence of the North-European cucumber (Cucumis sativus L.) unravels evolutionary adaptation mechanisms in plants. PLoS One 6:e22728

Wu T, Qin Z, Zhou X, Feng Z, Du Y (2010) Transcriptome profile analysis of floral sex determination in cucumber. J Plant Physiol 167:905-913

Xiao J, Jin R, Wagne D (2017) Developmental transitions: integrating environmental cues with hormonal signaling in the chromatin landscape in plants. Genome Biol 18:88

Yamaguchi N, Huang J, Xu Y, Tanoi K, Ito T (2017) Fine-tuning of auxin homeostasis governs the transition from floral stem cell maintenance to gynoecium formation. Nat Commun 8: 1125

Yamasaki S, Kazuto M (2009) Potential involvement of Cs1MMP in the arrest of sex organ development during sexual expression in cucumber (Cucumis sativus L.). J Jpn Soc Hort Sci 78:195-199

Yamasaki S, Fujii N, Takahashi H (2000) The ethylene-regulated expression of $C S-E T R 2$ and $C S-E R S$ genes in cucumber 
plants and their possible involvement with sex expression in flowers. Plant Cell Physiol 41:608-616

Yamasaki S, Fujii N, Matsuura S, Mizusawa H, Takahashi H (2001) The $M$ locus and ethylene-controlled sex determination in andromonoecious cucumber plants. Plant Cell Physiol 42:608-619

Yamasaki S, Fujii N, Takahashi H (2003a) Photoperiodic regulation of CS-ACS2, CS-ACS4 and CS-ERS gene expression contributes to the femaleness of cucumber flowers through diurnal ethylene production under short-day conditions. Plant Cell Environ 26:537-546

Yamasaki S, Fujii N, Takahashi H (2003b) Characterization of ethylene effects on sex determination in cucumber plants. Sex Plant Reprod 16:103-111

Yamasaki S, Yamakuchi R, Yamanaka S, Manabe K (2017) Potential involvement of cell cycle-related genes in the arrest of stamen development of female flowers during sex expression in cucumber (Cucumis sativus L.). Environ Control Biol 55:105-112

Yang L, Min C, Fuquan L et al (2000) Carpel of cucumber (Cucumis sativus L.) male flowers maintains early primordia characteristics during organ development. Chin Sci Bull 8: 729-733

Yin T, Quinn JA (1995) Tests of a mechanistic model of one hormone regulating both sexes in Cucumis sativus (Cucurbitaceae). Am J Bot 82:1537-1546

Zhang Y, Zhang X, Liu B, Wang W, Liu X, Chen C, Liu X, Yang $\mathrm{S}$, Ren H (2014a) A GAMYB homologue CsGAMYBI regulates sex expression of cucumber via an ethyleneindependent pathway. J Exp Bot 65:3201-3213

Zhang Y, Liu B, Yang S, An J, Chen C, Zhang X, Ren H (2014b) Cucumber DELLA homolog CsGAIP may inhibit staminate development through transcriptional repression of B class floral homeotic genes. PLoS One 9:e91804

Zhang Z, Mao L, Chen H, Bu F, Li G, Sun J, Li S, Sun H, Jiao C, Blakely R, Pan J, Cai R, Luo R, van de Peer Y, Jacobsen E, Fei Z, Huang S (2015) Genome-wide mapping of structural variations reveals a copy number variant that determines reproductive morphology in cucumber. Plant Cell 27:15951604

Zhang Y, Zhao G, Li Y, Mo N, Zhang J, Liang Y (2017) Transcriptomic analysis implies that GA regulates sex expression via ethylene-dependent and ethylene-independent pathways in cucumber (Cucumis sativus L.). Front Plant Sci 8:10

Zhang X, Lai Y, Zhang W, Ahmad J, Qiu Y, Zhang X, Duan M, Liu T, Song J, Wang H, Li X (2018) MicroRNAs and their targets in cucumber shoot apices in response to temperature and photoperiod. BMC Genomics 19:819

Publisher's note Springer Nature remains neutral with regard to jurisdictional claims in published maps and institutional affiliations. 